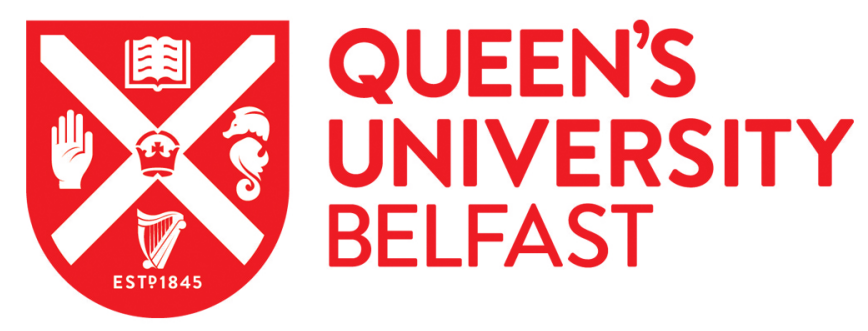

\title{
Chloride ingress into marine exposed concrete: A comparison of empirical- and physically- based models
}

Kim, J., McCarter, W. J., Suryanto, B., Nanukuttan, S., Basheer, P. A. M., \& Chrisp, T. M. (2016). Chloride ingress into marine exposed concrete: A comparison of empirical- and physically-based models. Cement and Concrete Composites. https://doi.org/10.1016/j.cemconcomp.2016.06.002

Published in:

Cement and Concrete Composites

Document Version:

Peer reviewed version

Queen's University Belfast - Research Portal:

Link to publication record in Queen's University Belfast Research Portal

Publisher rights

(C) 2016, Elsevier Ltd

This is an open access article published under a Creative Commons Attribution-NonCommercial-NoDerivs License

(https://creativecommons.org/licenses/by-nc-nd/4.0/), which permits distribution and reproduction for non-commercial purposes, provided the author and source are cited.

\section{General rights}

Copyright for the publications made accessible via the Queen's University Belfast Research Portal is retained by the author(s) and / or other copyright owners and it is a condition of accessing these publications that users recognise and abide by the legal requirements associated with these rights.

Take down policy

The Research Portal is Queen's institutional repository that provides access to Queen's research output. Every effort has been made to ensure that content in the Research Portal does not infringe any person's rights, or applicable UK laws. If you discover content in the Research Portal that you believe breaches copyright or violates any law, please contact openaccess@qub.ac.uk. 
Chloride ingress into marine exposed concrete: A comparison of empirical- and physically- based models

\author{
J. $\operatorname{Kim} *$ \\ W. J. McCarter *\# \\ B. Suryanto * \\ S. Nanukuttan ${ }^{+}$ \\ P. A. M. Basheer ${ }^{++}$ \\ T. M. Chrisp*
}

* School of Energy, Geoscience, Infrastructure and Society, Heriot Watt University, Edinburgh EH14 4AS, Scotland, UK

${ }^{+}$School of Planning, Architecture and Civil Engineering, Queen's University, Belfast BT7 1NN, N. Ireland, UK

${ }^{++}$School of Civil Engineering,

University of Leeds, Leeds LS2 9JT, UK

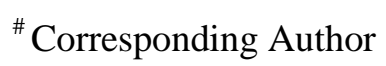

E-mail: w.j.mccarter@hw.ac.uk

Tel: +44 (0)131 4513318

Fax: +44 (0)131 4514617 


\section{$\underline{\text { Abstract }}$}

In establishing the reliability of performance-related design methods for concrete - which are relevant for resistance against chloride-induced corrosion - long-term experience of local materials and practices and detailed knowledge of the ambient and local micro-climate are critical. Furthermore, in the development of analytical models for performance-based design, calibration against test data representative of actual conditions in practice is required. To this end, the current study presents results from full-scale, concrete pier-stems under long-term exposure to a marine environment with work focussing on XS2 (below mid-tide level) in which the concrete is regarded as fully saturated and XS3 (tidal, splash and spray) in which the concrete is in an unsaturated condition. These exposures represent zones where concrete structures are most susceptible to ionic ingress and deterioration. Chloride profiles and chloride transport behaviour are studied using both an empirical model (erfc function) and a physical model (ClinConc). The time dependency of surface chloride concentration $\left(C_{s}\right)$ and apparent diffusivity $\left(D_{a}\right)$ were established for the empirical model whereas, in the ClinConc model (originally based on saturated concrete), two new environmental factors were introduced for the XS3 environmental exposure zone. Although the XS3 is considered as one environmental exposure zone according to BS EN 206-1:2013, the work has highlighted that even within this zone, significant changes in chloride ingress are evident. This study aims to update the parameters of both models for predicting the long term transport behaviour of concrete subjected to environmental exposure classes XS2 and XS3.

Keywords: concrete, full-scale testing, marine environment, modelling, durability, performance. 


\subsection{Introduction}

The most predominant process associated with reinforced concrete deterioration is the ingress of water contaminated with chloride either from deicing salt used for snow and ice control on roads for winter maintenance purposes or from the marine environment where, for example, bridges span tidal estuaries. Because the use of deicing salt is likely to continue for the foreseeable future, and concrete structures will always be placed in, or near, the marine environment, little can be done to prevent structures from being exposed to chloride salts. The premature deterioration of concrete structures due to chloride ingress and subsequent corrosion of the steel reinforcement is a worldwide problem and imparts a significant drain on maintenance resources, not only in terms of the remedial work required, but also in the costs associated with periodic inspections and testing together with indirect costs such as traffic delays and lost productivity. According to the survey by Nwaubani and Katsanos [1], the maintenance expenditure of many developed countries including the US, Canada, Japan, Australia and the UK resulting from the premature deterioration of concrete bridges was estimated to be in the range $0.01-0.1 \%$ of gross domestic product (GDP); in addition, the indirect costs due to traffic delays and lost productivity resulting from bridge maintenance and superstructure replacement programmes are more than ten times the direct cost of corrosion.

The deterioration of concrete structures exposed to chloride-rich environments is inevitable, hence the long-term performance of concrete assumes an important role in ensuring durable concrete structures. The concrete composition and the constituent materials need to be closely defined to enable the required level of performance to be maintained, hence the growing interest, and indeed need, for performance-based specifications. Performance-related methods - which are more relevant to corrosion resistance - consider, in a quantitative way, each relevant deterioration mechanism, the working life of the element or structure and the criteria that define the end of this working life (e.g. time to corrosion initiation). The level of knowledge of the ambient and local micro-climate is thus critical in establishing the reliability of performance-related design methods. 
Although BS EN 206 [2] still defines prescriptive design methods for durability, Section 5.3 .3 of this code allows for performance-related methods and defines concrete on the basis of an equivalent durability procedure (EDP); further detail on the EDP is presented in PD CEN/TR 16563 [3]. However, in order to fully implement a performance-based approach requires,

(i) long-term experience of local materials and practices, and on detailed knowledge of the local environment;

(ii) test methods based on approved and proven tests that are representative of actual conditions and have approved performance criteria; and,

(iii) analytical models that have been calibrated against test-data representative of actual conditions in practice.

Regarding (iii) above, a number of predictive models have been developed and have become increasingly more refined owing to our improved understanding the chloride transport mechanisms in concrete. These models range from simple, empirical models based on Fick's $2^{\text {nd }}$ law to determine the propagation of chloride within concrete [4-6] to more complex, physically-based models using the flux-balance system of equations. Regarding the latter, the ClinConc model [7, 8] focusses on the mechanisms occurring within the concrete, namely diffusion and chemical interactions; the STADIUM ${ }^{\circledR}$ model [9], which is a multi-ionic transport model and, in addition to diffusion and chemical interactions, considers electrical coupling of ions in the pore solution. The more sophisticated service-life prediction models become, most, if not all, cannot accurately predict the performance of a concrete in different environments without previously carrying out extensive calibration measurements [10] to evaluate, surface chloride concentrations, capillary porosity, chloride binding etc. 
It is evident that an additional refinement is required to both the physically-based model and empirical model to cover local conditions as these, ultimately, influence the long-term movement of chloride into concrete. This refinement enhances both models for predicting chloride transport in the target structure. To this end, this paper uses data obtained from an extensive chloride-profiling programme undertaken over an 8-year period, together with a more limited study at 20-years, to evaluate both empirically-based and physically-based models. The testing was undertaken on fullscale, concrete bridge pier-stems exposed to a marine environment represented by the following environmental classifications defined in BS EN 206 [2] and BS 8500-1 [11],

(i) XS1 - exposed to airborne salt but not in direct contact with seawater;

(ii) XS2 - permanently submerged which also includes all concrete below mid-tide level i.e. at a level were the concrete remains saturated and has little/no time to dry out; and,

(iii) XS3 - tidal, splash and spray zones.

This paper focusses on XS2 and XS3 exposure classes.

\subsection{Empirical and Physical Models for Chloride ingress in Concrete}

\subsection{Empirical (Fickian) model based on the erfe function}

Assuming that diffusion is the dominant transport mechanism, the chloride profile in concrete can be expressed through Fick's Law for one-dimensional diffusion as,

$$
\frac{\partial \mathrm{C}_{\mathrm{t}}}{\partial \mathrm{t}}=\mathrm{D}_{\mathrm{a}} \frac{\partial^{2} \mathrm{C}_{\mathrm{t}}}{\partial \mathrm{x}^{2}}
$$

Where, $C_{t}$ is the total chloride content (free and bound chloride) at the exposure time, $\mathrm{t}(\mathrm{sec})$ at depth of $x(\mathrm{~m})$ from the surface, $D_{a}$ is the apparent diffusion coefficient $\left(\mathrm{m}^{2} / \mathrm{s}\right)$. Provided that both the diffusion coefficient and surface chloride concentration are constant in the duration of exposure, 
the solution to (1) gives the basic empirical model which can be expressed in terms of the error function complement (erfc) as [12],

$$
C_{t}(x, t)=\left(C_{s}-C_{i}\right) \operatorname{erfc}\left(\frac{x}{2 \sqrt{D_{a} t}}\right)
$$

In this equation, $C_{s}$ is the equilibrium chloride content on the concrete surface and $C_{i}$ is the initial chloride content of the concrete before the exposure to the chloride environment. Hereinafter this will be referred to as the erfc model. The calculation is simple and convenient and, in addition, the values of parameters $C_{s}$ and $D_{a}$ can be easily estimated from experimental or field data using regression analysis. However, this model has limitations when applied to concrete [13-15] and a number of modifications have been proposed to account for the time-dependency of these parameters through aging factors, some of which are presented in Table 1 [16-24]. As the factors applied on $C_{s}$ and $D_{a}$, are determined empirically they can vary within wide limits [25-28]. If the values derived from a particular test are then used to predict the service life without consideration of environmental conditions, the predicted chloride ingress is likely to be incorrect. However, due to its simplicity and wide use, this formalism has been used in the current study to obtain the basic parameters which provide information on the long-term behaviour of chloride transport in concrete exposed to a marine environment.

\subsection{The ClinConc Model}

This is a physical model which uses a flux equation based on the principle of Fick's law [7,8]. A numerical solution is obtained using the mass balance equation combined with a non-linear chloride binding isotherm, with both free- and bound-chlorides considered in chloride transport. This can be summarised as, 


$$
\begin{gathered}
\frac{\partial \mathrm{q}_{\mathrm{cl}}}{\partial \mathrm{x}}=-\frac{\partial}{\partial \mathrm{x}}\left(\mathrm{D}_{\mathrm{o}} \frac{\partial \mathrm{C}_{\mathrm{f}}}{\partial \mathrm{x}}\right) \\
\frac{\partial \mathrm{C}_{\mathrm{t}}}{\partial \mathrm{t}}=\frac{\partial \mathrm{C}_{\mathrm{f}}}{\partial \mathrm{t}}+\frac{\partial \mathrm{C}_{\mathrm{b}}}{\partial \mathrm{t}}
\end{gathered}
$$

Where, $C_{t}, C_{f}$ and $C_{b}$ are, respectively, the total, free and bound chloride contents, $q_{c l}$ is the net flux of free chloride per unit area and $D_{0}$ is the intrinsic diffusion coefficient. The model input parameters include concrete mix proportions, binder components, curing temperature, environmental temperature and the chloride concentration in the solution to which the concrete is exposed. The 6-month chloride migration coefficient, obtained from the non-steady-state migration test [29], is the only input parameter which needs to be measured and there is no requirement for the surface chloride content of the concrete which can significantly influence the result when using the erfc solution. As chloride transport is modelled by pure diffusion, the model will only predict the chloride penetration profile in concrete exposed to a marine environment in which the concrete remains saturated. Chloride ingress in other zones can also be evaluated by changing the boundary (i.e. exposure) conditions which relate to the degree of contact of the concrete with sea-water [30]. It is difficult, however, to model the boundary condition quantitatively, especially in the splash and spray zones where chloride ingress by wave/spray action tends to be random.

In the current study, in order to reflect the randomness in the boundary conditions, two parameters are introduced which reflect the saturation condition of the concrete $\left(\mathrm{K}_{\mathrm{s}}\right)$ and the degree of contact with sea water $\left(\mathrm{K}_{\exp }\right)$. These are discussed in detail below. 


\section{Experimental Studies}

\subsection{Marine Exposure Conditions and Pier stem details}

The test-site was located on the southern causeway which leads on to the road-bridge which spans the Dornoch Firth in north-east Scotland (see Fig. 1(a)). The bridge, itself, was completed in 1991 and comprised a precast concrete deck which was incrementally launched over in-situ, reinforced concrete piers (Fig. 1(b)). A total of nine, full-size, pier-stems were cast and positioned at three different locations representing the environmental exposure conditions XS1, XS2 and XS3 defined above. Each pier-stem, weighing in excess of 10 tonnes, was 2-metres high and octagonal in crosssection with each face being $660 \mathrm{~mm}$. The pier-stems were cast in the steel formwork (Fig. 2(a)) which was used in the construction of the actual bridge-piers and reinforced with a combination of $32 \mathrm{~mm}$ and $40 \mathrm{~mm}$ diameter reinforcing bars in the form of a circular cage, with $16 \mathrm{~mm}$ diameter helical links (Fig. 2(b)). The cover to the reinforcement varies due to the circular cage arrangement and the pier stems-having an octagonal shape and gave a minimum cover to the main steel of $65 \mathrm{~mm}$ at the centre of each face. In the current study, only chloride data from two of the nine pier-stems are presented - one pier-stem for XS2 exposure and one for XS3 exposure. Reinforcement detailing, concrete mix (Table 2), formwork and cross-sectional dimensions (Fig. 2(c)) of the pierstems replicated those used in construction of the actual bridge. Furthermore, in order to simulate the full-height bridge piers, where water/chloride ingress can only occur through the sides of the piers, a waterproof coating was cast on the top of all the pier-stems.

On removal of the formwork after 1-week, the pier-stems were covered with polythene (Fig. 2(d)) before being transported and positioned at the marine site (approximately 35-days after casting). Fig. 3(a) presents a schematic of the positioning of the pier-stems and Fig. 3(b) shows the placement of the pier-stems at the test site. The use of a plain Portland cement concrete for the pier- 
systems (which was that used in the as-built bridge piers) allows evaluation of baseline/benchmarking measurements.

\subsection{Sampling and Chloride profiling}

The sampling was carried out biannually over the initial 8-years exposure during May and November - and a further, more limited, study was conducted at an exposure time of approximately 20 years. The pier-stems were placed in position in July 1991 and sampling started 16-months after placement. At each sampling point on the pier-stems, dust was collected using a 30mm diameter drill-bit at increments: $0-5,5-15,15-25,25-35,35-45,45-55,55-65 \mathrm{~mm}$ from the surface; the diameter of the drill-bit in relation to the maximum size of the aggregate $(20 \mathrm{~mm})$ was considered appropriate to reduce errors caused by drilling through aggregate particles. The drill-bit tool and drill-hole were cleaned between depth increments to reduce the possibility of cross-contamination of samples from different depths. On completion, the drill-hole was grouted with mortar. Powdered samples were analyzed for total chloride content (i.e. acid soluble) in accordance with BS 1881: Part 124 [31] and BS 6337: Part 4 [32]. In summary, samples were obtained at the following locations on all faces:

(a) Pier-stem 1: 0.2, and 1.0m above the base (XS2 environment in accordance with BS 8500-1 i.e. concrete below mid-tide level);

(b) Pier-stem 2: 0.2, 1.0, and $1.8 \mathrm{~m}$ above the base (XS3 environment: concrete in the tidal and splash zones);

In relation to the current work, only faces 1, 2 and 8 (seaward) on pier stems 1 and 2 are considered for chloride profiles; furthermore, regarding the XS3 environment defined above, this is further divided into three zones and indicated on Fig. 3(a): the high-tidal zone (denoted XS3:H-T), the lowsplash zone (denoted XS3:L-S) and the high-splash zone (denoted XS3:H-S). Approximately 44 
months after placement, six, 50mm diameter cores (approximately $60 \mathrm{~mm}$ in length) were taken from faces 4, 5 and 6 of pier-stem 3 to evaluate the porosity and degree of saturation of the concrete. The cores were dry-cut and it is assumed that this has negligible influence on the moisture state of the core. After removal from the pier-stem, each core was tightly wrapped with several layers of cling-film.

The temperature of the concrete was also monitored by embedding thermistors within the surface $50 \mathrm{~mm}$ of small concrete slabs positioned at the same locations as the pier-stems. The 3-day average temperature of the concrete is presented in Fig. 3(c) which covers the months the chloride sampling programme was undertaken.

\subsection{Migration Coefficient}

In order to use the ClinConc model, the 6-month migration coefficient is required. Samples for the migration test were cast using the same mix specification as that used in the pier stems (see Table 2) thereby conforming to the reference concrete defined in the equivalent durability procedure specified in Section 6.2 of PD CEN/TR 16563:2013 [3]. Additional 28-day compressive strength tests were also carried out using $100 \mathrm{~mm}$ cubes and, for migration testing, 100mm (diameter) $\times 300 \mathrm{~mm}$ cylinders were cast in PVC moulds; 24-hours after casting, the samples were placed in curing tank. After 6-months curing, three concrete disks were extracted from the middle of the samples using diamond saw and the migration coefficient determined following the test procedure specified in NT build 492 [29]. The results for compressive strength and migration coefficient of the reference concrete are summarised in Tables 2 and 4 respectively (mean values).

\section{Results and Discussion}

In this section, the erfc solution is used in conjunction with the field data to evaluate surface chloride concentration and diffusion coefficient for concrete exposed to a marine environment. The 
ClinConc model is also used to calculate theoretical chloride profiles which are then compared to the measured chloride profiles and modifications proposed to this model to account for different marine exposure conditions.

\subsection{Erfc solution - Aging Factors l}

In the erfc function, the diffusion coefficient is assumed as constant. Generally, however, this is not the case and to account for the time-dependency of the apparent diffusion coefficient, $D_{a}$, it is more appropriately modelled by the following equation (see Table 1),

$$
D_{a}(\mathrm{t})=D_{R}\left(\frac{t_{R}}{t}\right)^{m}
$$

where, $D_{R}$ is the reference diffusion coefficient $\left(\mathrm{m}^{2} / \mathrm{s}\right)$ at exposure time, $t_{r}$ (years), $t$ is time at which the diffusion coefficient is required and the exponent, $m$, is an aging factor. The time-dependency of the surface chloride concentration, $C_{s}(t)$, is also considered and the following are used in the current work (see Table 1),

$$
\begin{aligned}
& C_{S}(\mathrm{t})=\mathrm{C}_{o} t^{n} \\
& C_{S}(\mathrm{t})=\mathrm{C}_{o} \sqrt{t}
\end{aligned}
$$

The aging exponents, $m$ and $n$, and the surface-chloride coefficient, $\mathrm{C}_{\mathrm{o}}$, are determined empirically.

For illustrative purposes, Figs. 4(a)-(d) present the chloride profiles at different exposure times for XS2 exposure and XS3 exposure, with XS3 exposure comprising the three zones: H-T, L-S and H-S defined above. The values presented represent the mean value for samples taken from faces 1,2 and 8. Although only the mean values have been presented, Figures 5(a)-(d) present the statistical information to show the variation in the chloride concentration with time and exposure, in this instance at a depth of $2.5 \mathrm{~mm}$ (denoted $\mathrm{Cl}_{2.5}$ ) - this depth was chosen for illustrative purposes as it displayed the greatest variability in comparison to the other depths. The error bars on the data 
markers represent one standard deviation on either side of the mean value presented. In moving through a height of approximately $3.5 \mathrm{~m}$ i.e. from the XS2 zone to the XS3:H-T zone, the chloride concentration at this depth decreases by almost a factor of five. In addition, the CoV is greatest for data in the XS3:L-S and XS3:H-S zones where splash and spray action on the concrete surface tends to be more random in nature when compared to the XS2 and XS3:H-T exposure zones.

From the chloride profiles such as those presented in Fig. 4, the surface-chloride concentration, $\mathrm{C}_{\mathrm{s}}$, and apparent diffusion coefficient, $\mathrm{D}_{\mathrm{a}}$, were evaluated at all exposure times and are presented in Figs. 6-9 for the four environments. Equations (5), (6) and (7) were regressed on these data and the resulting fits are presented on these Figures with the aging factors, $m$ and $n$, and the surface-chloride coefficient, $\mathrm{C}_{\mathrm{o}}$, summarised in Table 3. In evaluating these factors (including $\mathrm{R}^{2}$ values), outliers indicated by 'open' marks on Figs 7-9, have been removed from the process; however, for completeness, Table 3 also presents the respective factors (within brackets) using all data points in the regression analysis. It becomes evident that in moving from the XS2 and XS3:H-T zones to the XS3:L-S and XS3:H-S zones, there is increasing scatter in the data due to the more random contact of splash/spray action with the surface as was noted above.

The aging factor for diffusion coefficient obtained in the XS2 zone was evaluated as 0.19 and is comparable with the value of $m=0.20$ suggested by Bamforth [33] or CEM I concrete and that used in LIFE 365 [34], whereas an indicative value of $m=0.3$ for CEM I concrete with w/c $<0.6$ has also been reported [35]. The work has shown that the aging factor is also dependent upon the exposure environment as it increased in the splash zone (XS3:L-S and XS3:H-S); regarding the latter, a value of $m=0.37$ has been proposed [25] for CEM I concrete in the tidal/splash-zone. In relation to the surface chloride concentration for marine exposed concrete, recommended values for use in design range, typically, from $\mathrm{C}_{\mathrm{s}}=4.2 \%$ for $\mathrm{XS} 2$ exposure to $\mathrm{C}_{\mathrm{s}}=2.2 \%$ for the XS3:H-T, L-S and H-S zones [36]. Other studies $[37,38]$ have reported $C_{s}$ values in the range $1.5-4.0 \%$ by weight of cement for concrete in the marine tidal-zone (i.e. XS3:H-T zone). Measurements made on marine 
concrete structures ranging from 8 to 40 years old [26] have also reported $C_{s}$ values between 1.83.9\%. Based on the field data presented, the surface chloride concentration after 5-years exposure is evaluated as $5.96 \%$ for XS2; $2.88 \%$ for XS3:H-T; $2.38 \%$ for XS3:L-S and $1.23 \%$ for XS3:H-S exposure. It is evident that the values of surface chloride concentration evaluated from this study lie within the range of previously published work; however, it should be emphasised that the values obtained from this study relate to specific exposure conditions, concrete mix proportions etc.

Models developed by the Japanese Society of Civil Engineers [5] present the following equation for estimating the apparent diffusion coefficient, $\mathrm{D}_{\mathrm{a}}$, of ordinary Portland cement (CEM I) concrete,

$$
\log _{10} \mathrm{D}_{\mathrm{a}}=-3.9(w / c)^{2}+7.2(w / c)-14 \quad\left(\mathrm{~m}^{2} / \mathrm{s}\right)
$$

where $w / c$ is the water/cement ratio. It is interesting to note that the effects of environment and time are not considered. For the concrete used in the pier-stems $(w / c=0.4), \mathrm{D}_{\mathrm{a}}$ is evaluated as $1.8 \times 10^{-}$ ${ }^{12} \mathrm{~m}^{2} / \mathrm{s}$ from equation (8). Using the parameters for XS2 environment presented in Table 3, this value would be equivalent to approximately 18-years exposure. The same specification also presents a value of $13 \mathrm{~kg} / \mathrm{m}^{3}$ for surface chloride concentration for concrete exposed to seawater in the splash-zone which equates to approximately $2.83 \%$ by weight of cement for the concrete used in the pier-stems; this value would be equivalent to approximately 8-years exposure in the XS3:L-S zone and 34-years in the XS3:H-S zone.

\subsection{ClinConc Model - Environmental Factors}

As noted above, the ClinConc model only applies to concrete exposed to the XS2 environment i.e. where the concrete remains fully saturated. Fig. 10 presents both the chloride profiles in Fig. 4(a) and those predicted by the ClinConc model at each respective time. The initial input parameters for the ClinConc model are presented in Table 4. The migration coefficient evaluated from the laboratory tests (which is the only experimentally determined input parameter for the ClinConc 
model) agrees well with published data [39, 40]. The model predicts well the chloride profiles through the surface $60 \mathrm{~mm}$ of cover. In the current work, in order to reflect the differing degrees of concrete saturation and exposure condition, we have introduced two new environmental factors denoted, respectively, $\mathrm{K}_{\mathrm{S}}$ and $\mathrm{K}_{\mathrm{exp}}$.

As the ClinConc model assumes the concrete to be fully saturated, we have introduced $\mathrm{K}_{\mathrm{S}}$ to account for influence of the degree of pore saturation on the diffusion coefficient. In formulating $\mathrm{K}_{\mathrm{S}}$, the following relationship has been adapted from the work of Kumar [41] which relates the degree of pore saturation, $S_{r}\left(0<S_{r}<1\right)$, water/cement ratio, $w / c$, and the apparent diffusion coefficient, $D_{a}$,

$$
\mathrm{K}_{\mathrm{S}}=\frac{\mathrm{D}_{\mathrm{a}}}{\mathrm{D}_{\text {sat }}}=\mathrm{S}_{\mathrm{r}}^{4.863-3.441 \mathrm{w} / \mathrm{c}}
$$

where $D_{\text {sat }}$ the diffusion coefficient in the fully saturated state. $D_{\text {sat }}$ is evaluated within the ClinConc model and is based on the 6-month diffusion coefficient measured by the rapid chloride migration test noted above. Evaluation of $K_{S}$, requires a knowledge of the degree of saturation of the concrete and was obtained gravimetrically from cores taken from pier-stem 3 (see Fig. 3), detailed above, by saturation and subsequent drying at $105^{\circ} \mathrm{C}$. The porosity was evaluated as $15.5 \%$ and the degree of saturation was $80 \%$; hence, for $w / c=0.4, K_{S}=0.45$ using equation (9) above. Although this factor was determined for XS1 environment, due to the proximity of pier-stem 1 with pier-stem 2 it was used for both the low-splash and high-splash zones and would represent a lower-bound value of saturation for concrete in the splash-zone. A value of $\mathrm{K}_{\mathrm{S}}=1.0$ has been used for XS3 (H-T zone) and XS2 environments.

In order to account for the effect of exposure condition on chloride accumulation, an environmental factor, $K_{\text {exp }}$, is introduced into the ClinConc model. The details for equations (10)-(12) below have 
been presented elsewhere [8]; however, in summary, the relationship between total, $C_{t}$, free, $C_{f}$ and bound, $C_{b}$, chlorides can be written,

$$
C_{t}=\frac{\varepsilon\left(C_{f}+C_{b}\right)}{B_{c}} \times 100 \text { mass \% of binder }
$$

where $\varepsilon$ is the porosity and $B_{c}$ the cementitious binder content. Also, the relationship between $C_{b}$ and $C_{f}$ is also given as,

$$
C_{b}=f_{t} k_{O H} K_{b} k_{T b} \alpha_{t} C_{f}^{\beta}
$$

In this expression, $f_{t}$ is a time-dependent factor for binding capacity; $k_{O H}$ and $K_{b}$ are, respectively, factors related to hydroxyl content and gel content; $k_{T b}$ is a binding activation function for temperature; $\alpha_{\mathrm{t}}$ is a time-dependent chloride binding factor and $\beta$ is a chloride binding constant. The total chloride content could now be considered as a function of only the free-chloride content i.e.

$$
C_{t}=\Phi\left(C_{f}\right)
$$

where $\Phi$ represents the functional relationship within the ClinConc model. As the environmental exposure conditions will influence the free chloride concentration, the $K_{\exp }$ factor noted above is now introduced as follows,

$$
C_{t}=K_{\exp } \times \Phi\left(C_{f}\right)
$$

We have determined the $K_{\text {exp }}$ factor by comparing the chloride profile computed from the ClinConc model (which assumes $S_{r}=100 \%$ ) with that measured in the pier-stems. The three XS3 marine environments, H-T, L-S and H-S zones, are considered separately due to their varying degrees of contact with the sea-water. For illustrative purposes, Fig. 11(a) presents the chloride distribution 
after 6.8 years exposure for the XS3:H-T environment; also presented on this Figure is chloride profile predicted from the ClinConc model which includes, in addition to the input parameters in Table 4 , the environmental parameter, $K_{S}$, as determined above $\left(\mathrm{K}_{\mathrm{S}}=1.0\right.$ for XS3:H-T). In order to evaluate $K_{\text {exp }}$ the predicted ClinConc profile is adjusted by incrementally modifying the $K_{\text {exp }}$ factor such that it maps onto the actual profile. The adjusted curve, and the $K_{\exp }$ factor associated with the adjusted curve, is presented on this Figure. This process was undertaken for all the available profiles at this exposure and the averaged $K_{\text {exp }}$ value presented in Table 5; using these values for $K_{S}$ and $K_{\text {exp }}$, Fig. 11(b) presents the measured profiles and the predicted profile from the modified ClinConc model and, for reasons of clarity, only four exposure times are presented. This fitting procedure was replicated for XS3:L-S and XS3:H-S environments and Figs. 12(a) and 12(b) present the measured and predicted profiles using the environmental factors displayed on the Figure and summarised in Table 5. The Figures show that as the degree of contact with the sea-water decreases, $K_{\text {exp }}$ decreases resulting in a lower chloride content at the surface and, subsequently, leading to lower ingress of chloride.

Figs. 12(a) and (b) indicate that the modified ClinConc model tends to overpredict the chloride profile within the surface $\sim 20 \mathrm{~mm}$ at short exposure times. The possible reason for this feature is attributed to the fact that a higher binding capacity is used in the ClinConc model compared to the actual conditions. The chloride binding capacity is influenced by various factors such as temperature, moisture-content, free chloride content, hydroxyl ion concentration and exposure time [42]. The higher the hydroxyl ion content in the capillary pore water, the less will be the chloride binding capacity due to chemical competition between hydroxides and chlorides for adsorption sites $[43,44]$. Hydroxyl ions can be leached in the submerged zone causing a reduction in their concentration, whilst the hydroxyl ion concentration in the splash zone could be significantly higher. The result of higher hydroxyl ion concentration will lead to lower chloride binding, especially at the earlier exposure times whereas higher hydroxyl ion concentration will result in lower chloride 
binding. The hydroxyl ion content in the XS2 and XS3:H-T zones quickly reach a limiting value as the hydroxides are leached out from concrete, whilst less contact of the sea-water in XS3:L-S and XS3:H-S zones a maintain higher hydroxyl ion content in concrete. This could be the reason in the overestimated values for ClinConc model in the XS3:L-S and XS3:H-S zones at short exposure times.

\subsection{Time to corrosion}

In the design of concrete structures, two limit states are generally considered: the ultimate limitstate (ULS) and the serviceability limit-state (SLS); however, a third limit state has been introduced - the initiation limit-state (ILS) [45]. Whilst both the ULS and SLS mean the loss of structural performance of the reinforced concrete, the ILS closely depicts the potential loss. In the evaluation of the service-life of concrete structures, the limit-state thus needs to be defined and, for reinforced concrete exposed to chloride-rich environments, this is generally determined by the ILS as the corrosion propagation period can be unpredictable compared to the initiation period. As in all limitstates, the load/resistance inequality must be satisfied and in relation to the ILS, the resistance is determined by the chloride-threshold level for corrosion initiation $\left(\mathrm{Cl}_{\text {thres }}\right)$ on the steel surface which is positioned at depth, $x$, and the environmental loading is represented by the chloride-content at this depth after exposure time, $t$. The load/resistance inequality can be written,

$$
C l(x, t) \leq C l_{\text {thres }}
$$

If corrosion initiation defines the end of service life or the ILS has been reached, then the time, $t$, this is normally specified as 50 years or 100 years [11]. The chloride threshold level can vary over a wide range, typically from $0.2 \%$ to $2.2 \%$ by weight of cement $[36,46,47]$ so it would be incorrect to specify a chloride threshold level as a single deterministic value. For example, the degree of 
exposure the structure has with seawater has a significant influence on the chloride threshold level as oxygen availability is dictated by the level of saturation of the concrete. Values of $2.1 \%$ in the submerged zone and $0.8 \%$ for the other zones have been quoted [48].

In this study, the chloride threshold level for the calculation of time to corrosion initiation is considered as $0.4 \%$ by weight of cement in the XS3:L-S and XS3:H-S zones as there will be oxygen availability, and 0.4 and $2.0 \%$ by weight of cement in XS3:H-T and XS2 zones. The time to ILS was estimated using three models:

(i) the ClinConc model with input parameters presented in Table 4 and environmental factors, $\mathrm{K}_{\mathrm{S}}$ and $\mathrm{K}_{\mathrm{exp}}$, in Table 5;

(ii) the erfc model using a power-law relationship (Equation(6)) for surface chloride concentration; and,

(iii) the erfc model using the square-root-time relationship (Equation (7)) for surface chloride concentration.

The time-dependency of apparent diffusion coefficient defined by equation (5) above is used in both (ii) and (iii). The aging factors for both apparent diffusion coefficient and surface chloride concentration evaluated from the field data presented in Table 3 have been used. The predicted initiation times for each model are presented in Table 6. All three models show good agreement in XS2 exposure although this is possibly to be expected as the concrete is in a fully saturated state and time-scales for $C l_{\text {thres }}$ to be reached tend to be relatively short ( $<20$ years); furthermore, there is little to choose between erfc models in (ii) and (iii) above as the predicted surface chloride concentrations are similar. In the XS3:H-T zone all three models predict similar ILS times for $C l_{\text {thres }}=0.4 \%$; it is only at the higher $C l_{\text {thres }}$ value that model (iii) predicts a lower initiation time (27 years). We attribute this to the square-root-time relationship considerably over-predicting the 
surface chloride build-up in the longer-term; this feature would have the effect of shortening the initiation time. In the XS3:H-S zone, all models show good agreement; in the XS3:L-S zone, however, the ClinConc model predicts a shorter initiation time perhaps indicating that the $K_{\exp }$ factor should be lower than 0.24 and possibly closer to the value in the XS3:H-S zone.

It is interesting to note that although all models predict that for $C l_{\text {thres }}=0.4 \%$ the steel should be actively corroding in the XS2 and XS3:H-T zones, visual inspection of the pier-stems after approximately 20-years exposure show no evidence of rust staining or spalling (see Fig. 13). Furthermore, the profiles at 20-years (Figs 4(a) and (b)) indicate that the chloride concentration at $50 \mathrm{~mm}$ (depth of link steel) is $1.98 \%$ for XS2 exposure and $1.53 \%$ for XS3:H-T exposure, which is considerably higher than the $0.4 \%$ threshold level and clearly warrants further investigation.

\section{Conclusions and Concluding Comments}

Chloride transport in concrete exposed to a marine environment was evaluated using both the erfc (Fickian) solution and the ClinConc model. The study undertook an extensive chloride profiling programme based on field-data obtained from full-scale, concrete pier-stems in the XS2 and XS3 environmental exposure zones over an extended period of time. As a consequence, the derived quantities surface chloride concentration, $C_{s}$, apparent diffusion coefficient, $D_{a}$, would represent a true reflection of reinforced concrete structures exposed to a marine environment. The work has also shown the variable nature of both $C_{s}$ and $D_{a}$. Both $C_{s}$ and $D_{a}$ displayed a time-dependency and the data were used to develop aging factors $(m, n)$ and a surface-chloride coefficient $\left(C_{o}\right)$ for the erfc (empirical) model. To describe the various environmental conditions for ClinConc model, two environmental factors were employed which were used for the description of chloride transport in other zones in addition to the submerged zone on which the ClinConc model is based. From the results in this study, the following conclusions can be drawn, 
1) It was confirmed that the degree of chloride ingress was highly variable and sensitive to the environmental conditions, particularly in the zones exposed to splash and spray action where the degree of contact of the concrete surface with the seawater is more random than concrete in the tidal zone, which remains in a saturated or near-saturated condition. Aging factors for both apparent diffusion coefficient $(m)$ and surface chloride concentration $\left(C_{o}, n\right)$ were obtained from the field data and it was shown that these were dependent upon the exposure zone.

2) The field-data were used to recalibrate the ClinConc model by the introduction of two new environmental factors - a factor related to the degree of pore saturations, $K_{S}$, and a factor related to the chloride binding capacity of the cementitious binder, $K_{\text {exp }}$. Values based on field measurements were presented and it was evident that both factors decreased as the degree of contact of the seawater with the concrete surface reduced and became more random.

3) The time to corrosion was evaluated in the each zone using the erfc solution and modified ClinConc model. In the tidal zone, two chloride threshold values were used $0.4 \%$ and $2.0 \%$ by weight of cement and the chloride threshold level of the splash zone was used $0.4 \%$ by weight of cement. The empirical model and the modified ClinConc model predicted similar ILS times.

As durability design concepts move from a deterministic method to a probabilistic approach [49-51], it is then necessary to secure a significant data-base on field measurements for concrete exposed to different environmental actions; the present work presented makes such a contribution in relation to marine exposed concrete. 


\section{Acknowledgements}

Aspects of the work presented form part of the concrete durability programme into monitoring and improving the performance of structural concrete in bridges and in the development of performance-based testing procedures undertaken for Transport Scotland and the Engineering and Physical Sciences Research Council, UK (Research Grants EP/G025096, EP/G02152X and EP/I005846). The views expressed in this paper are those of the Authors and not necessarily those of Transport Scotland. 


\section{References}

[1] Nwaubani SO, Katsanos A. Effect of Alternative De-icers on the Corrosion Resistance of Reinforced Concrete Bridges and Highway Structures. In: Developments in Corrosion Protection, Aliofkhazraei M (Ed.), InTech; 2014 (ISBN 978-953-51-1223-5; doi: $10.5772 / 57551)$.

[2] BS EN 206:2013 Concrete-Part 1: Specification, performance, production and conformity. British Standards Institution, London; 2013.

[3] PD CEN/TR 16563:2013. Principles of the equivalent durability procedure. British Standards Institution, London; 2013 (ISBN 978-0-580-81434-1).

[4] Thomas MDA, Bamforth PB. Modelling chloride diffusion in concrete: Effect of fly ash and slag. Cem Concr Res. 1999;29(4):487-95.

[5] Japan Society of Civil Engineers (JSCE). Standard specifications for concrete structures 2007 Maintenance: JSCE;2010 (ISBN: 978-4-8106-0754-3).

[6] Farahani A, Taghaddos H, Shekarchi M. Prediction of long-term chloride diffusion in silica fume concrete in a marine environment. Cem Concr Compos. 2015;59(May):10-7.

[7] Tang L. Chloride Transport in Concrete - Measurement and Prediction. PhD thesis. Gothenburg, Sweden, Chalmers University of Technology; 1996.

[8] Tang L. Engineering expression of the ClinConc model for prediction of free and total chloride ingress in submerged marine concrete. Cem Concr Res. 2008;38(8-9):1092-7.

[9] Marchand J. Modeling the behavior of unsaturated cement systems exposed to aggressive chemical environments. Mater Struct. 2001;34(4):195-200.

[10] Nielsen EP. The durability of white Portland cement to chemical attack. Report BYG DTU R-084, Chapter 1. ISBN 87-7877-147-1, 2004.

[11] BS EN 8500-1:2015. Concrete Complementary British Standard to BS EN 206-1-Part 1: Method of specifying and guidance for the specifier. British Standards Institution, London; 2006.

[12] Collepardi M, Marcialis A, Turriziani R. Penetration of Chloride Ions into Cement Pastes and Concretes. J Am Ceram Soc. 1972;55(10):534-5. 
[13] Crank J. The mathematics of diffusion. 2nd ed. Oxford: Clarendon Press. ISBN 0-19853344-6; 1975.

[14] Saetta A, Scotta R, Vitaliani R. The numerical analysis of chloride penetration in concrete. ACI Mater J. 1993;90(5):441-51.

[15] Andrade C, Díez JM, Alonso C. Mathematical Modeling of a Concrete Surface "Skin Effect" on Diffusion in Chloride Contaminated Media. Adv Cem Based Mater. 1997;6(2):39-44.

[16] Mangat PS, Molloy BT. Prediction of long term chloride concentration in concrete. Mater Struct. 1994;27(6):338-46.

[17] Maage M, Helland S, Poulsen E, Vennesland O, Carlsen JE. Service life prediction of existing Concrete structures exposed to marine environment. ACI Mater J. 1996;93(6):6028.

[18] Stanish K, Thomas M. The use of bulk diffusion tests to establish time-dependent concrete chloride diffusion coefficients. Cem Concr Res. 2003;33(1):55-62.

[19] Kassir MK, Ghosn M. Chloride-induced corrosion of reinforced concrete bridge decks. Cem Concr Res. 2002;32(1):139-43.

[20] Amey SL, Johnson DA, Miltenberger MA, Farzam H. Predicting the service life of concrete marine structures: an environmental methodology. ACI Struct J. 1998;95(2):205-14.

[21] Costa A, Appleton J. Chloride penetration into concrete in marine environment-Part II: Prediction of long term chloride penetration. Mater Struct. 1999;32(5):354-9.

[22] Maheswaran T, Sanjayan JG. A semi-closed-form solution for chloride diffusion in concrete with time-varying parameters. Mag Concr Res. 2004;56(6):359-66.

[23] Petcherdchoo A. Time dependent models of apparent diffusion coefficient and surface chloride for chloride transport in fly ash concrete. Constr Build Mater. 2013;38(January):497-507.

[24] Pack S-W, Jung M-S, Song H-W, Kim S-H, Ann KY. Prediction of time dependent chloride transport in concrete structures exposed to a marine environment. Cem Concr Res. 2010;40(2):302-12.

[25] Lindvall A. Original quantification of the environmental parameters in the Duracrete chloride ingress model. In: NILSSON L-O, editor. Nordic Mini Seminar and fib TG 55 
meeting (Prediction models for chloride ingress and corrosion initiation in concrete structures). Göteborg, Sweden: Department of Building Materials, Chalmers University of Technology; 2001.

[26] Polder RB, de Rooij MR. Durability of marine concrete structures: field investigations and modelling. Heron. 2005;50(3):133-53 (http://heronjournal.nl/50-3/1.pdf accessed 8th March 2016)

[27] van Breugel K, Schlangen E, Copuroglu O, Ye G. Modelling and predicting effects of deterioration mechanisms. In: Soutsos M, editor. Concrete Durability;2009, 124-145. doi 10.1680/cdapgttdodcs.35171.

[28] Audenaert K, Yuan Q, De Schutter G. On the time dependency of the chloride migration coefficient in concrete. Constr Build Mater. 2010;24(3):396-402.

[29] NT Build 492. Concrete, mortar and cement-based repair materials: Chloride migration coefficient from non-steady-state migration experiments. NORDTEST; 1999.

[30] Tang L. ClinConc model for prediction of chloride penetration into concrete-from the original to the latest modifications. In: NILSSON L-O, editor. Nordic Mini Seminar and fib TG 55 meeting (Prediction models for chloride ingress and corrosion initiation in concrete structures). Göteborg, Sweden: Department of Building Materials, Chalmers University of Technology; 2001.

[31] BS EN 1881-124:1988. Testing Concrete - Part 124: Methods for analysis of hardened concrete. British Standards Institution, London; 1988.

[32] BS EN 6337-4:1984. General methods of chemical analysis - Part 4: Method for determination of chloride ions by potentiometry. British Standards Institution, London; 1984.

[33] Bamforth PB. The derivation of input data for modelling chloride ingress from eight-year UK coastal exposure trials. Mag Concr Res. 1999;51(2):87-96.

[34] Ehlen M. LIFE-365 Service life prediction model, v. 2.1-Users Manual. 2012.

[35] Markeset G. Service Life Predictions of Marine Concrete Structures - Consequences of Uncertainties in Model Parameters In: NILSSON L-O, editor. Nordic Mini Seminar and fib TG 55 meeting (Prediction models for chloride ingress and corrosion initiation in concrete structures). Göteborg, Sweden,: Department of Building Materials, Chalmers University of Technology; 2001. 
[36] Bamforth PB, Price WF, Emerson M. An international review of chloride ingress into structural concrete, Contractor Report 359. Report 1303S/96/9092. 1997.

[37] Thomas MDA, Matthews JD. Performance of pfa concrete in a marine environment-10year results. Cem Concr Compos. 2004;26(1):5-20.

[38] Lindvall A. Chloride ingress data from field and laboratory exposure - Influence of salinity and temperature. Cem Concr Compos. 2007;29(2):88-93.

[39] Tang L, Utgenannt P. Chloride ingress and reinforcement corrosion in concrete under deicing highway environment - a study after 10 years exposure. SP Report 2007:76; SP Technical Research Institute of Sweden, Building Technology and Mechanics, Borås; 2007 (ISBN 978-91-85829-09-5).

[40] Nanukuttan SV, Basheer PAM, McCarter WJ, Tang L, Holmes N, Chrisp TM, Starrs G, Magee B. The performance of concrete exposed to marine environments: Predictive modelling and use of laboratory/on site test methods. Constr Build Matls. 2015; 93(Sept):831-840.

[41] Kumar A. Water flow and transport of chloride in unsaturated concrete. Master thesis. Saskatoon, Canada, University of Saskatchewan; 2010.

[42] Yuan Q, Shi C, De Schutter G, Audenaert K, Deng D. Chloride binding of cement-based materials subjected to external chloride environment - A review. Constr Build Mater. 2009;23(1):1-13.

[43] Sandberg P. Studies of chloride binding in concrete exposed in a marine environment. Cem Concr Res. 1999;29(4):473-7.

[44] Tritthart J. Chloride binding in cement II. The influence of the hydroxide concentration in the pore solution of hardened cement paste on chloride binding. Cem Concr Res. 1989;19(5):683-91.

[45] Muigai R, Moyo P, Alexander M. Durability design of reinforced concrete structures: a comparison of the use of durability indexes in the deemed-to-satisfy approach and the fullprobabilistic approach. Mater Struct. 2012;45(8):1233-44.

[46] Browner RD. Design prediction of the life for reinforced concrete in marine and other chloride environments. Durability of building materials. 1982;1(2):113-25. 
[47] Angst U, Elsener B, Larsen CK, Vennesland Ø. Critical chloride content in reinforced concrete - A review. Cem Concr Res. 2009;39(12):1122-38.

[48] Lay S. Prediction models for chloride ingress and corrosion initiation in concrete structures. In: NILSSON L-O, editor. Nordic Mini Seminar and fib TG 55 meeting (Prediction models for chloride ingress and corrosion initiation in concrete structures). Göteborg, Sweden: Department of Building Materials, Chalmers University of Technology; 2001.

[49] Gjørv OE. Durability design and quality assurance of major concrete infrastructure. Adv Concr Constr. 2013;1(1):45-63.

[50] Altmann F, Mechtcherine V. Durability design strategies for new cementitious materials. Cem Concr Res. 2013;54(December):114-25.

[51] Samarakoon SM, K.; SM, Sælensminde J. Condition assessment of reinforced concrete structures subject to chloride ingress: A case study of updating the model prediction considering inspection data. Cem Concr Comp. 2015;60(July):92-8. 


\section{Captions for Figures}

Fig. 1 (a) Location of marine exposure site; (b) showing the bridge spanning the Dornoch Firth estuary; and (c) exposure zone on bridge piers replicated at test-site adjacent to the Dornoch bridge.

Fig. 2 (a) Steel formwork used in construction of pier-stems; (b) reinforcement cage used in pier-stems (detailing the same as the Dornoch bridge); (c) pier-stems under construction; and (d) curing of pier-stems prior to being transported to exposure site.

Fig. 3 (a) Schematic diagram showing position of pier-stems, exposure zones and sampling points; (b) pier-stems in position - pier-stems marked '1' and '2' used in current work; and (c) variation in temperature within the concrete cover-zone (surface 50mm).

Fig. 4 Chloride profiles for (a) XS2 exposure; (b) XS3 High-Tidal; (c) XS3 Low Splash; and (d) XS3 High Splash.

Fig. 5 Variation in chloride concentration at a depth of $2.5 \mathrm{~mm}\left(\mathrm{Cl}_{2.5}\right)$ from surface and the coefficient of variation (CoV) for (a) XS2 exposure; (b) XS3 High Tidal; (c) XS3 Low Splash; and (d) XS3 High Splash (Note: error bars on chloride concentration represent \pm 1 standard deviation).

Fig. 6 Temporal variation in (a) surface chloride concentration, $C_{s}$; and (b) apparent diffusion coefficient, $D_{a}$ for XS2 exposure. Regression equations are summarised in Table 3.

Fig. 7 Temporal variation in (a) surface chloride concentration, $C_{s}$; and (b) apparent diffusion coefficient, $D_{a}$ for XS3 High Tidal exposure. Regression equations are summarised in Table 3.

Fig. 8 Temporal variation in (a) surface chloride concentration, $C_{s}$; and (b) apparent diffusion coefficient, $D_{a}$ for XS3 Low Splash exposure. Regression equations are summarised in Table 3. 
Fig. 9 Temporal variation in (a) surface chloride concentration, $C_{s}$; and (b) apparent diffusion coefficient, $D_{a}$ for XS3 High Splash exposure. Regression equations are summarised in Table 3.

Fig. 10 Measured chloride profiles and profiles predicted from ClinConc model for XS2 exposure.

Fig. 11 (a) Adjustment of profile predicted by ClinConc model by introduction of environmental factors, $K_{s}$, and $K_{\text {exp. }}$; and, (b) measured profiles and profiles predicted from ClinConc model using environmental parameters for XS3 High Tidal exposure.

Fig. 12 Measured profiles and profiles predicted from ClinConc model using environmental parameters for (a) XS3 Low Splash exposure; and, (b) XS3 High Splash exposure.

Fig. 13 Visual inspection of pier-stems after approximately 20 years exposure show no external signs of corrosion (e.g. rust-staining, spalling): (a) pier-stem 1 with mid-tide level indicated; and (b) pier-stem 2 with high-tide level indicated. 
Table.1 Aging functions used in erfc solution.

\begin{tabular}{c|c|c}
\hline $\begin{array}{c}\text { Surface Chloride } \\
\text { concentration, } \mathrm{C}_{\mathrm{S}}\end{array}$ & Apparent diffusion coefficient $\left(\mathrm{D}_{\mathrm{a}}\right)$ & Reference \\
\hline$C_{o}$ (constant) & $D_{a}(t)=\frac{D_{R}}{1-m}\left(\frac{t_{R}}{t}\right)^{m}$ & {$[16]$} \\
\hline$C_{o}($ constant $)$ & $D_{a}(t)=D_{R}\left(\frac{t_{R}}{t}\right)^{m}$ & {$[17]$} \\
\hline$C_{o}($ constant $)$ & $D_{a}(t)=\frac{D_{R}}{(1-m)} t_{R}^{m}\left(\frac{t^{1-m}-t_{I}^{1-m}}{t-t_{I}}\right)$ & {$[18]$} \\
\hline$C_{o}\left(1-e^{-n t}\right)$ & $D_{a}($ constant $)$ & {$[19]$} \\
\hline$C_{o} t$ & $D_{a}($ constant $)$ & {$[20]$} \\
\hline$C_{o} \sqrt{t}$ & $D_{a}(t)=D_{R}\left(\frac{t_{R}}{t}\right)^{m}$ & {$[21]$} \\
\hline$C_{o} t^{n}$ & $D_{a}(t)=\frac{D_{R}}{(1-m)}\left[\left(\frac{t_{R}}{t}\right)^{m}-\frac{t_{R}}{t}\right]$ & {$[22]$} \\
\hline$C_{o}\left[1-e^{-n(t-t)}\right]$ & $D_{R}\left[\left(1+\frac{t_{I}}{t_{E}}\right)^{1-m}-\left(\frac{t_{I}}{t_{E}}\right)^{1-m}\right]\left(\frac{t_{R}}{t_{E}}\right)^{m} t_{E}$ & {$[23]$} \\
\hline$C_{o} \sqrt{t}$ & $D_{a}=\frac{D_{R}}{1-m}\left[\begin{array}{c}D_{R} \\
(1-m)\end{array}\right)^{m}$ & {$[24]$} \\
\hline$C_{o}[\ln (\beta t+1)]+k$ & $D_{a}(t)=\frac{t_{R}}{(1-m}$ & \\
\hline
\end{tabular}

Note: $C_{o}, m, \mathrm{n}, k$ and $\beta$ are regression values, $\mathrm{t}_{\mathrm{R}}$ the reference time; $\mathrm{D}_{\mathrm{R}}$ the diffusion coefficient at time $t_{\mathrm{R}} ; t_{I}$ the time at the first exposure to chlorides; $t_{E}$ the time of exposure to chlorides, and $t$ is the age of the concrete.

Table 2: Concrete mix proportions used in pier-stems

\begin{tabular}{ccccccccc}
\hline OPC & $20 \mathrm{~mm}$ & $10 \mathrm{~mm}$ & fines & Plasticiser & Retarder & w/c & Slump & $\mathrm{f}_{28}$ \\
$\mathrm{~kg} / \mathrm{m}^{3}$ & $\mathrm{~kg} / \mathrm{m}^{3}$ & $\mathrm{~kg} / \mathrm{m}^{3}$ & $\mathrm{~kg} / \mathrm{m}^{3}$ & $1 / \mathrm{m}^{3}$ & $1 / \mathrm{m}^{3}$ & $\mathrm{~mm}$ & $\mathrm{MPa}$ \\
\hline 460 & 700 & 350 & 700 & $1.80^{*}$ & $1.80^{* *}$ & 0.4 & 110 & $63.0(65.3)$ \\
\hline
\end{tabular}

- ordinary Portland cement: CEM I:42.5N / ASTM Type I

* Sika FN ** Sika FR

$\mathrm{f}_{28}$ : 28-day compressive strength determined on $100 \mathrm{~mm}$ cubes for the pier-stems. Figure in brackets represents compressive strength determined on $100 \mathrm{~mm}$ cubes for migration test samples. 
Table 3: Aging exponents ( $m$ and $n$ ) and surface chloride coefficients $\left(\mathrm{C}_{\mathrm{o}}\right)$ evaluated from chloride profiles using the empirical (erfc) model. Note: in calculating these values the outlier(s) indicated by open markers on Figs 7-9 have been removed from the regression; however, for completeness, the number in brackets represents the best-fit parameters with outliers included.

\begin{tabular}{|c|c|c|c|c|c|}
\hline \multicolumn{2}{|l|}{ Parameter } & XS2 & XS3: H-T & XS3: L-S & XS3: H-S \\
\hline \multicolumn{2}{|l|}{ Reference time, $t_{R}$ (years) } & 1.3 & 1.3 & 1.3 & 1.3 \\
\hline \multicolumn{2}{|l|}{$\begin{array}{l}\text { Reference diffusion } \\
\text { coefficient, } D_{R}\left(\times 10^{-12} \mathrm{~m}^{2} / \mathrm{s}\right)\end{array}$} & 2.96 & 2.12 & 1.48 & $1.59(0.84)$ \\
\hline Age factor & $m$ & 0.19 & $0.10(0.16)$ & 0.54 & $0.48(0.067)$ \\
\hline \multirow{2}{*}{$\begin{array}{l}\text { Time dependency of surface } \\
\text { chloride content, Eq (6) }\end{array}$} & $C_{o}$ & 3.80 & $2.19(2.01)$ & $1.27(1.26)$ & $0.62(0.56)$ \\
\hline & $n$ & 0.28 & $0.17(0.19)$ & $0.39(0.36)$ & $0.43(0.47)$ \\
\hline $\begin{array}{l}\text { Time dependency of surface } \\
\text { chloride content, Eq ( } 7 \text { ) }\end{array}$ & $C_{o}$ & 2.48 & $1.15(1.11)$ & $1.07(1.01)$ & $0.56(0.53)$ \\
\hline
\end{tabular}

Table 4: Input parameters for ClinConc model

\begin{tabular}{c|c}
\hline Input parameter & Value \\
\hline $\begin{array}{c}\text { Cement content } \\
\left(\mathrm{kg} / \mathrm{m}^{3}\right)\end{array}$ & 460 \\
\hline Water Content $\left(1 \mathrm{tr} / \mathrm{m}^{3}\right)$ & 184 \\
\hline Aggregate $\left(\mathrm{kg} / \mathrm{m}^{3}\right)$ & 1750 \\
\hline $\begin{array}{c}\text { Average Temperature } \\
\left({ }^{\circ} \mathrm{C}\right)\end{array}$ & 9 \\
\hline $\begin{array}{c}\text { Concrete age at first } \\
\text { exposure }(\text { days })\end{array}$ & 35 \\
\hline $\begin{array}{c}\text { Exposure duration } \\
(\text { years })\end{array}$ & $\begin{array}{c}1.3,1.8,2.3,2.8,3.3, \\
4.2,5.1,5.5,6.3, \\
6.8,7.3,20^{*}\end{array}$ \\
\hline $\begin{array}{c}\text { Seawater chloride } \\
\text { content }(\mathrm{g} / \mathrm{l})\end{array}$ & 19.6 \\
\hline $\begin{array}{c}\text { Migration coefficient at } \\
6 \text { months }\left(\mathrm{m}^{2} / \mathrm{s}\right)^{* *}\end{array}$ & $\begin{array}{c}8.9 \times 10^{-12} \\
\left(0.2 \times 10^{-12}\right)\end{array}$ \\
\hline
\end{tabular}

* 20 year data obtained only for XS2 and XS3:H-T zones

** Mean value from migration tests. Value in brackets is the standard deviation. 
Table 5: Environmental factors used in ClinConc model for each zone determined from field data (number in brackets represent the standard deviation).

\begin{tabular}{c|c|c|c|c}
\hline $\begin{array}{c}\text { Environmental } \\
\text { factors }\end{array}$ & XS2 & XS3: H-T & XS3: L-S & XS3: H-S \\
\hline $\mathrm{K}_{\mathrm{S}}$ & 1 & 1 & 0.46 & 0.46 \\
\hline $\mathrm{K}_{\exp }$ & 1 & $0.45(0.013)$ & $0.24(0.023)$ & $0.14(0.011)$ \\
\hline
\end{tabular}

Table 6: The predicted time to attain critical chloride concentration $\left(C l_{\text {thres }}\right)$ at $50 \mathrm{~mm}$ in each exposure zone.

\begin{tabular}{|c|c|c|c|c|c|c|}
\hline \multirow{4}{*}{ Model } & \multicolumn{6}{|c|}{ Time to reach $C l_{\text {thres }}$ (years) } \\
\hline & \multicolumn{2}{|c|}{$\mathrm{XS} 2$} & \multicolumn{2}{|c|}{ XS3:H-T } & XS3:L-S & XS3:H-S \\
\hline & \multicolumn{2}{|c|}{$C l_{\text {thres }}$} & \multicolumn{2}{|c|}{$C l_{\text {thres }}$} & $C l_{\text {thres }}$ & $C l_{\text {thres }}$ \\
\hline & $2 \%$ & $0.4 \%$ & $2 \%$ & $0.4 \%$ & $0.4 \%$ & $0.4 \%$ \\
\hline Modified ClinConc & 19 & 6.0 & 45 & 9.5 & 35 & 54 \\
\hline $\begin{array}{c}\text { Erfc + power type } \\
(\operatorname{Eq}(6))\end{array}$ & 16 & 5.2 & 51 & 10 & 63 & 63 \\
\hline $\begin{array}{c}\text { Erfc }+ \text { square root type } \\
(\operatorname{Eq}(7))\end{array}$ & 14 & 5.3 & 27 & 9.3 & 52 & 55 \\
\hline
\end{tabular}




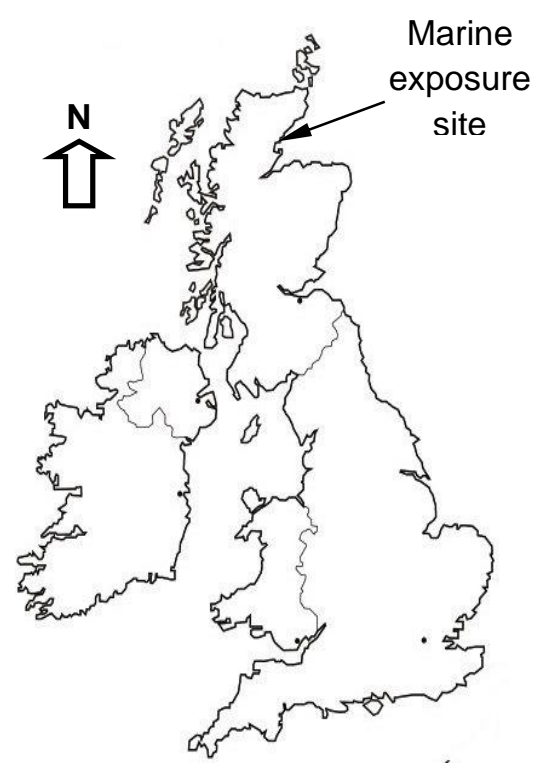

Fig. 1(a) 




Fig. 1(b)

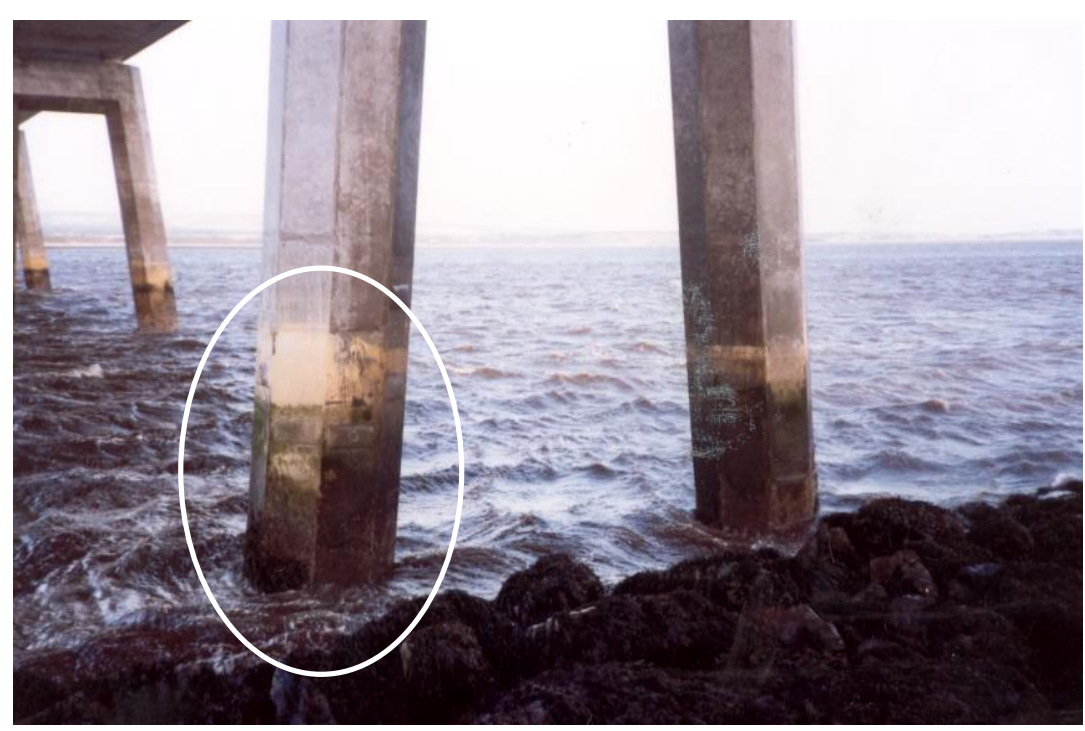

Zone replicated at test site

Fig. 1(c) 


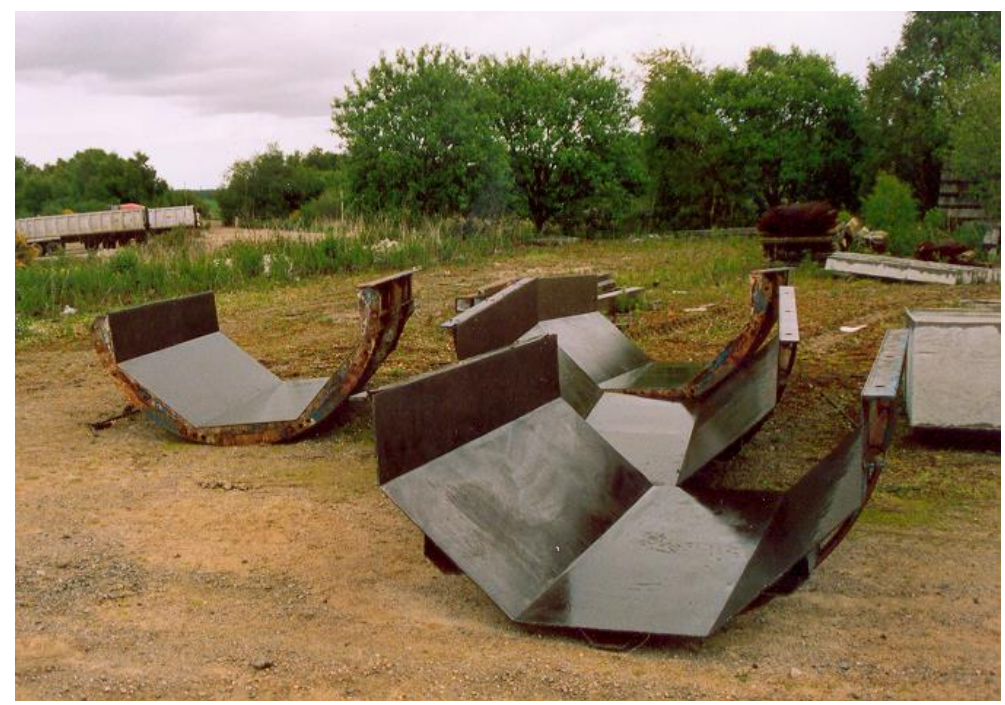

(a)

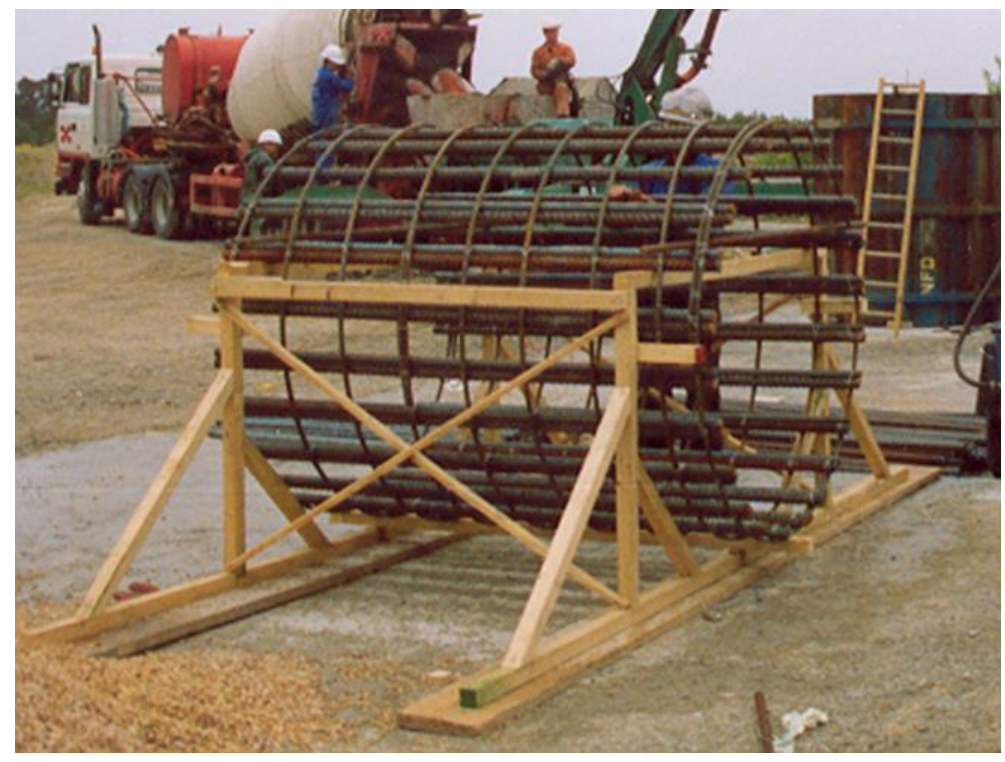

(b) 


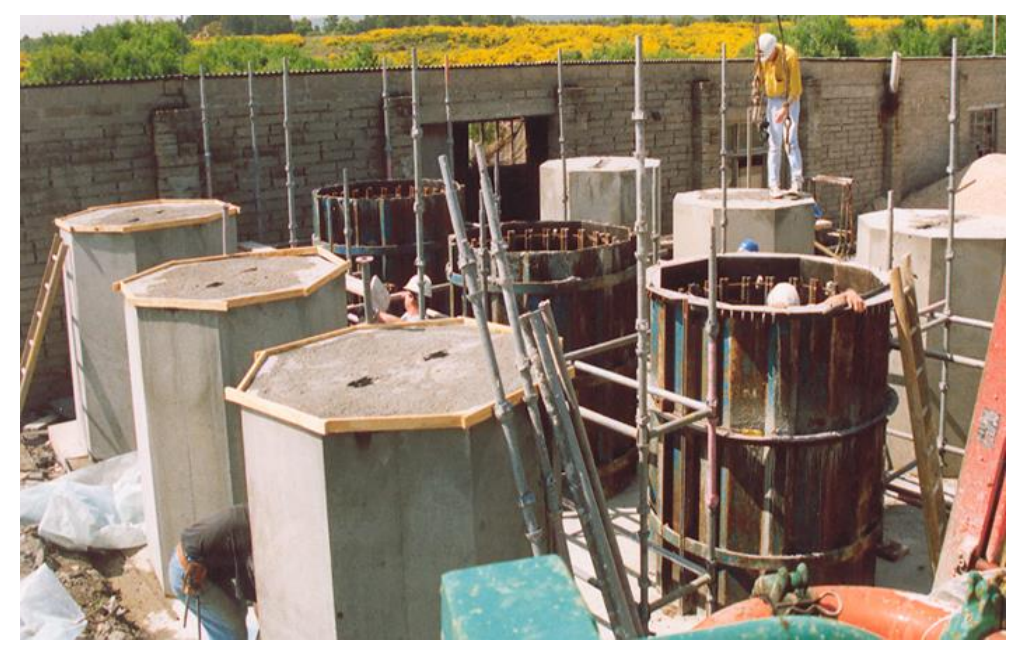

(c)

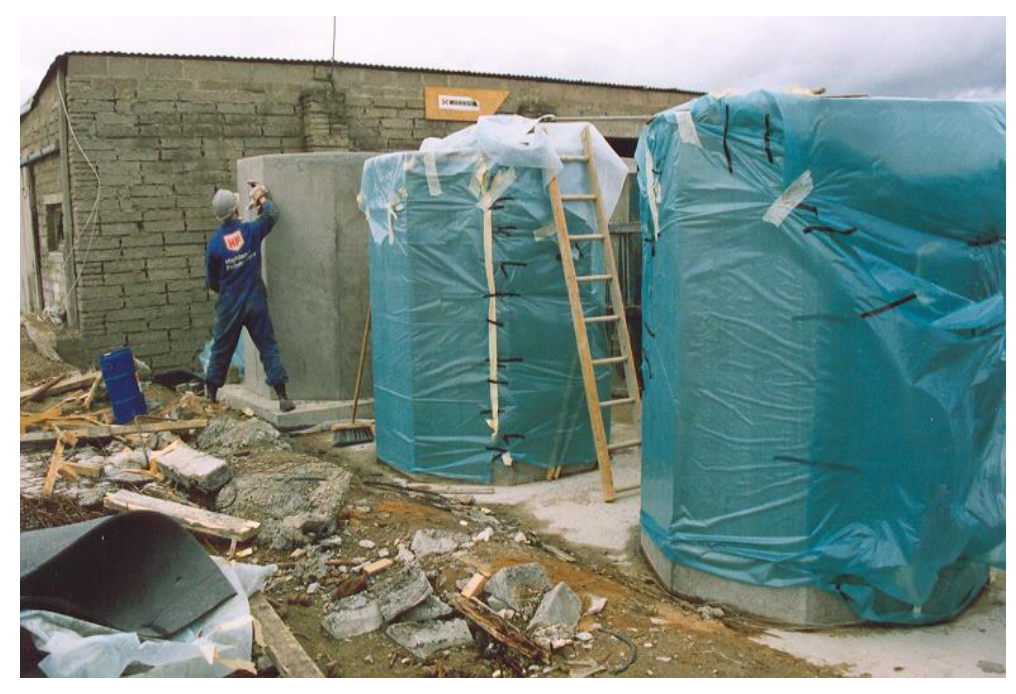

(d)

Fig. 2 


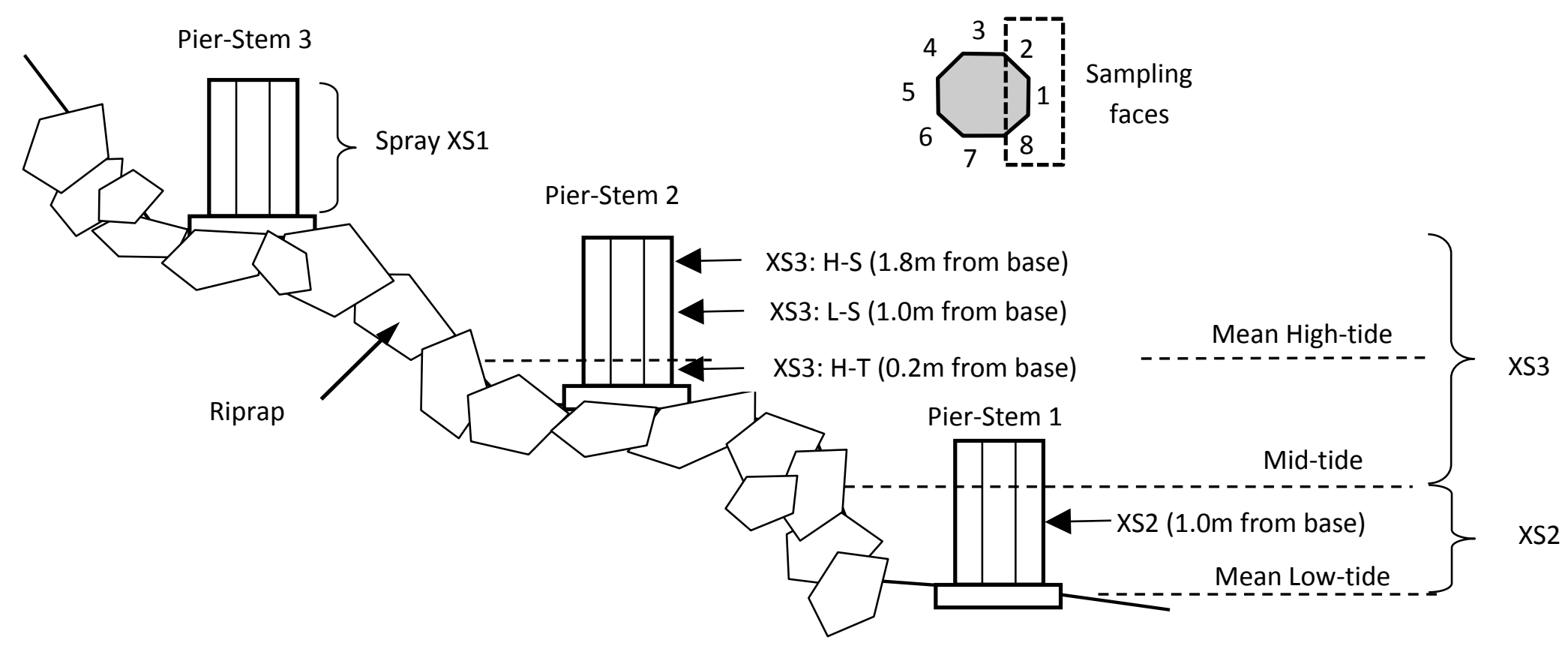

(a) 


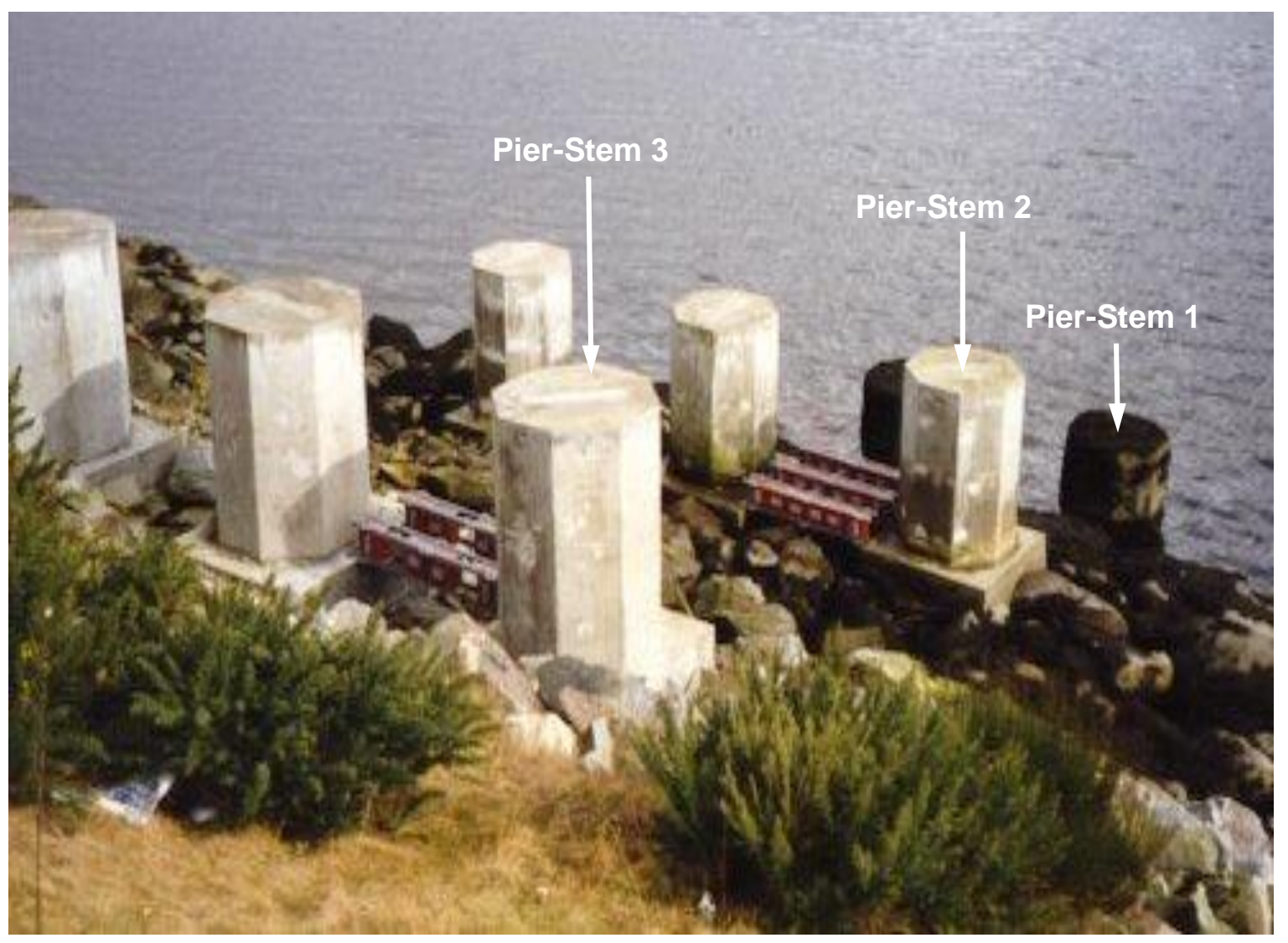

(b) 


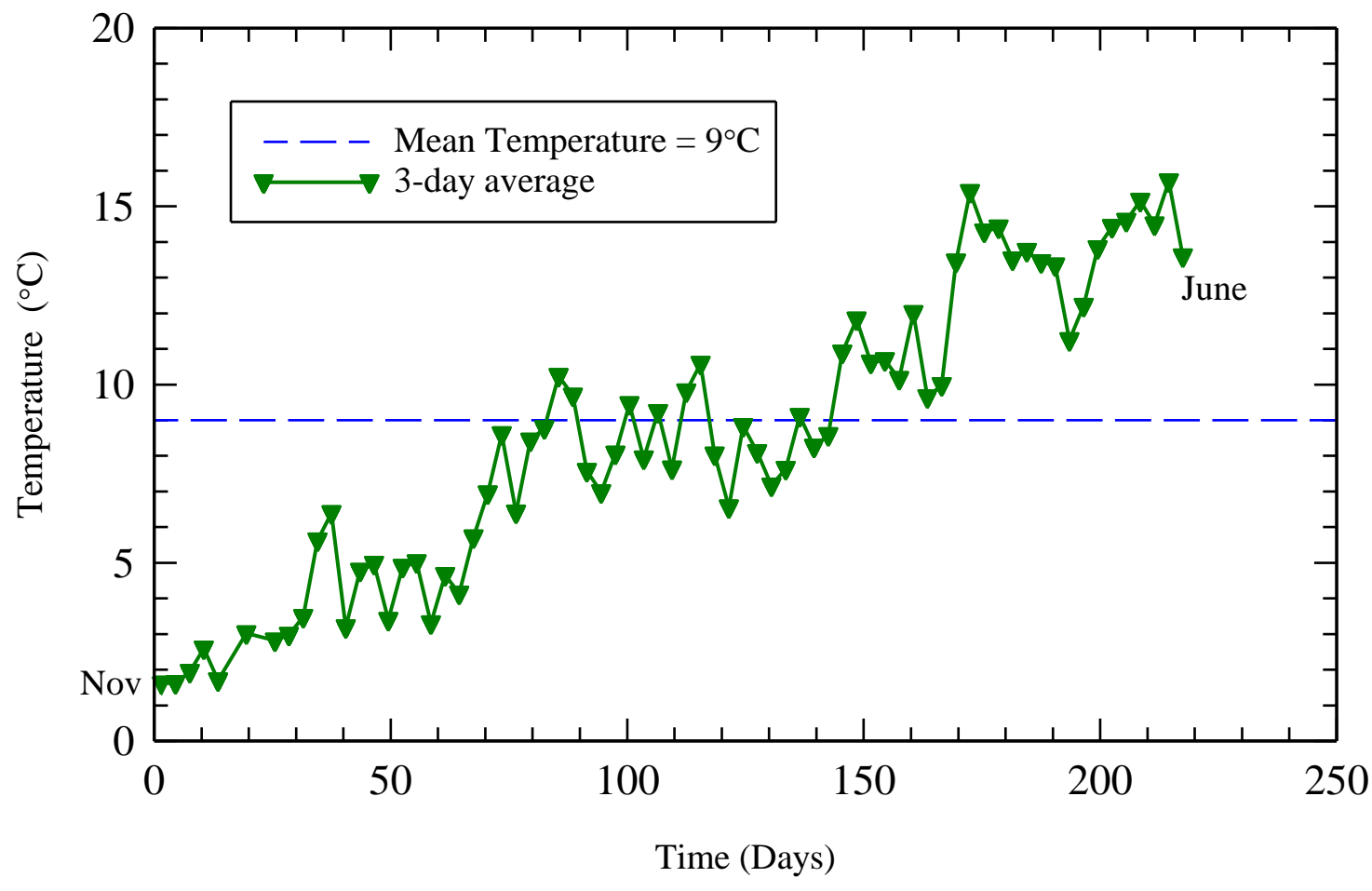

(c)

Fig. 3 
(a)



(b)




(c)

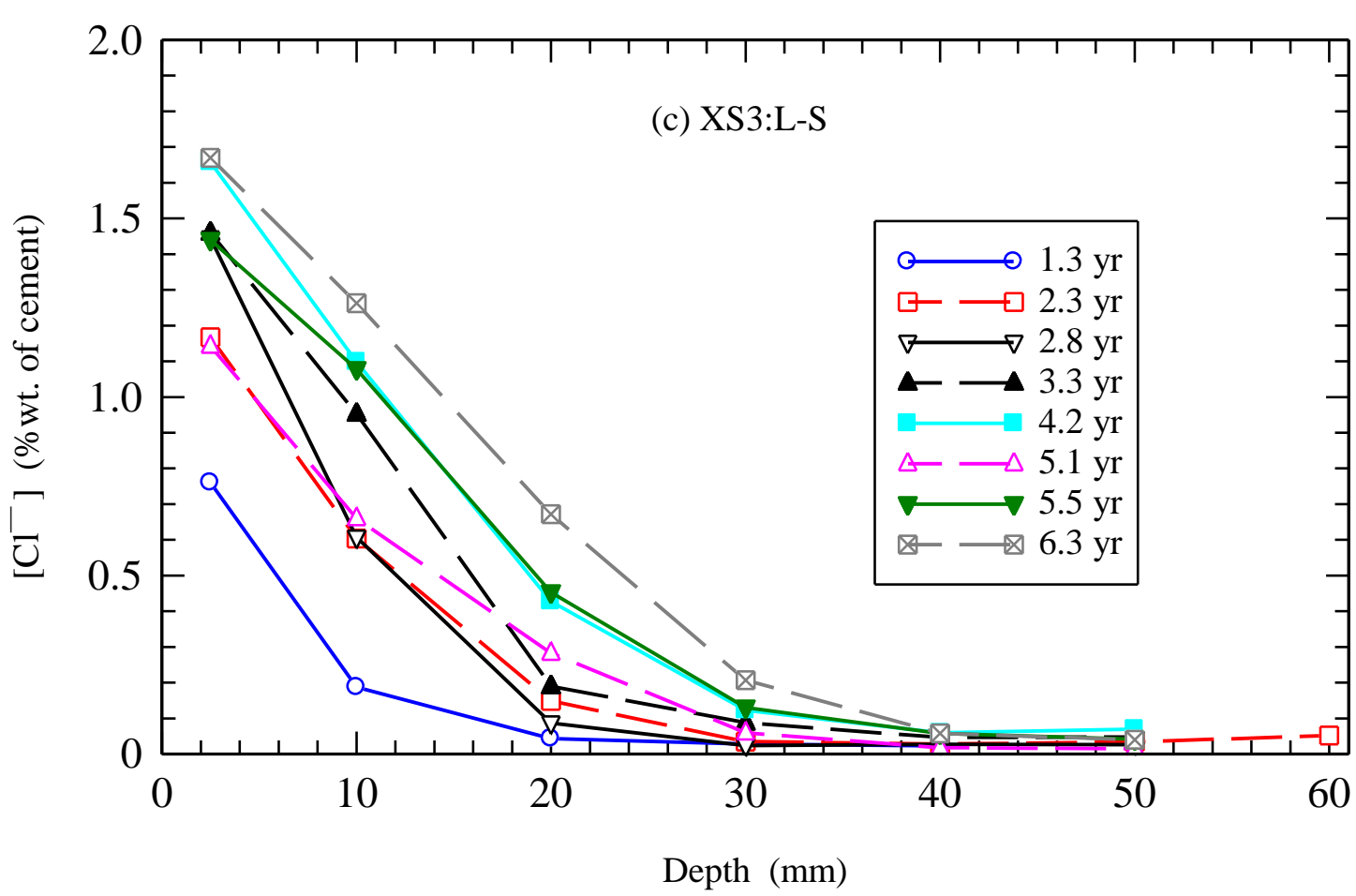

(d)

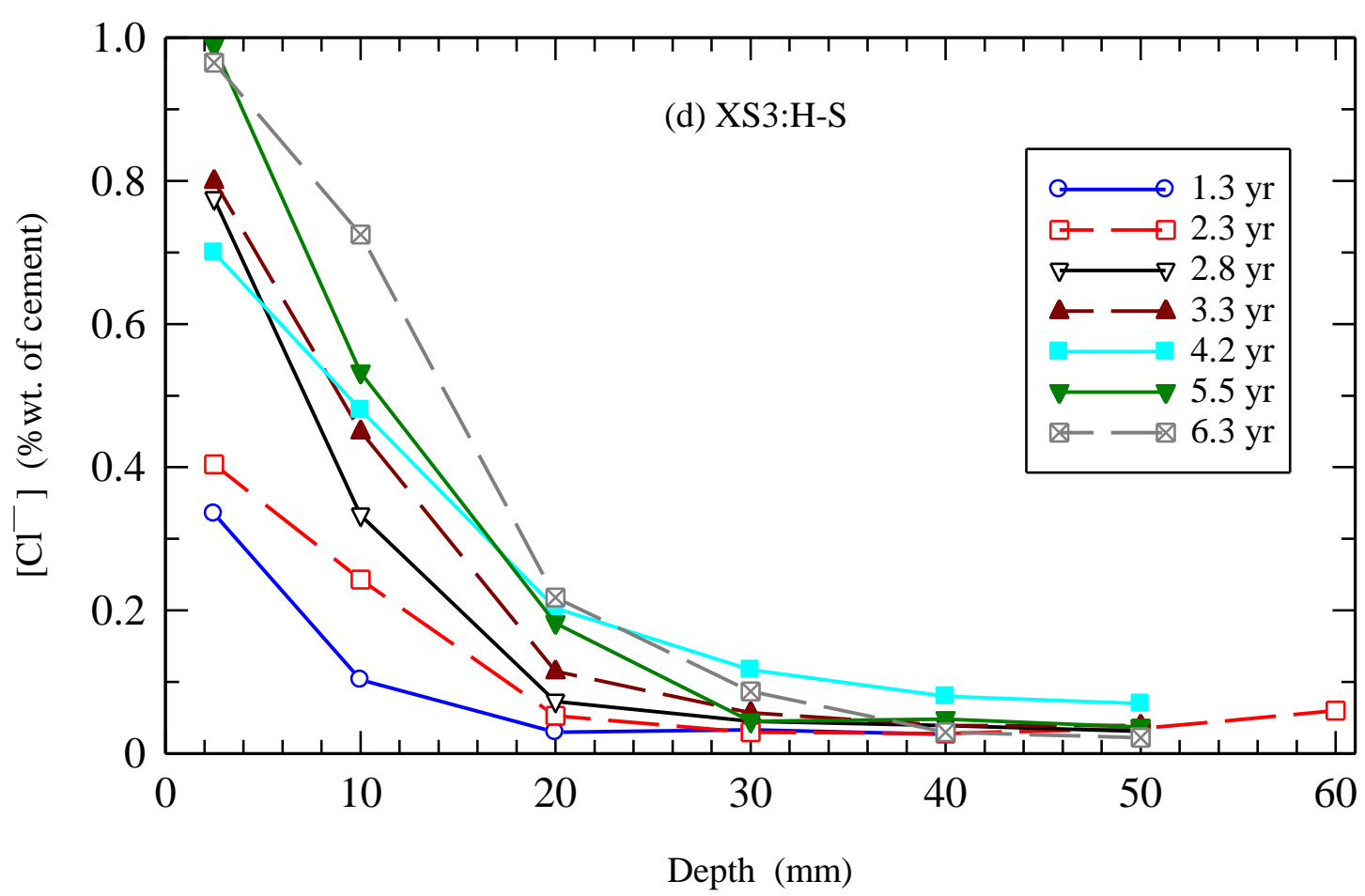

Fig. 4 
(a)

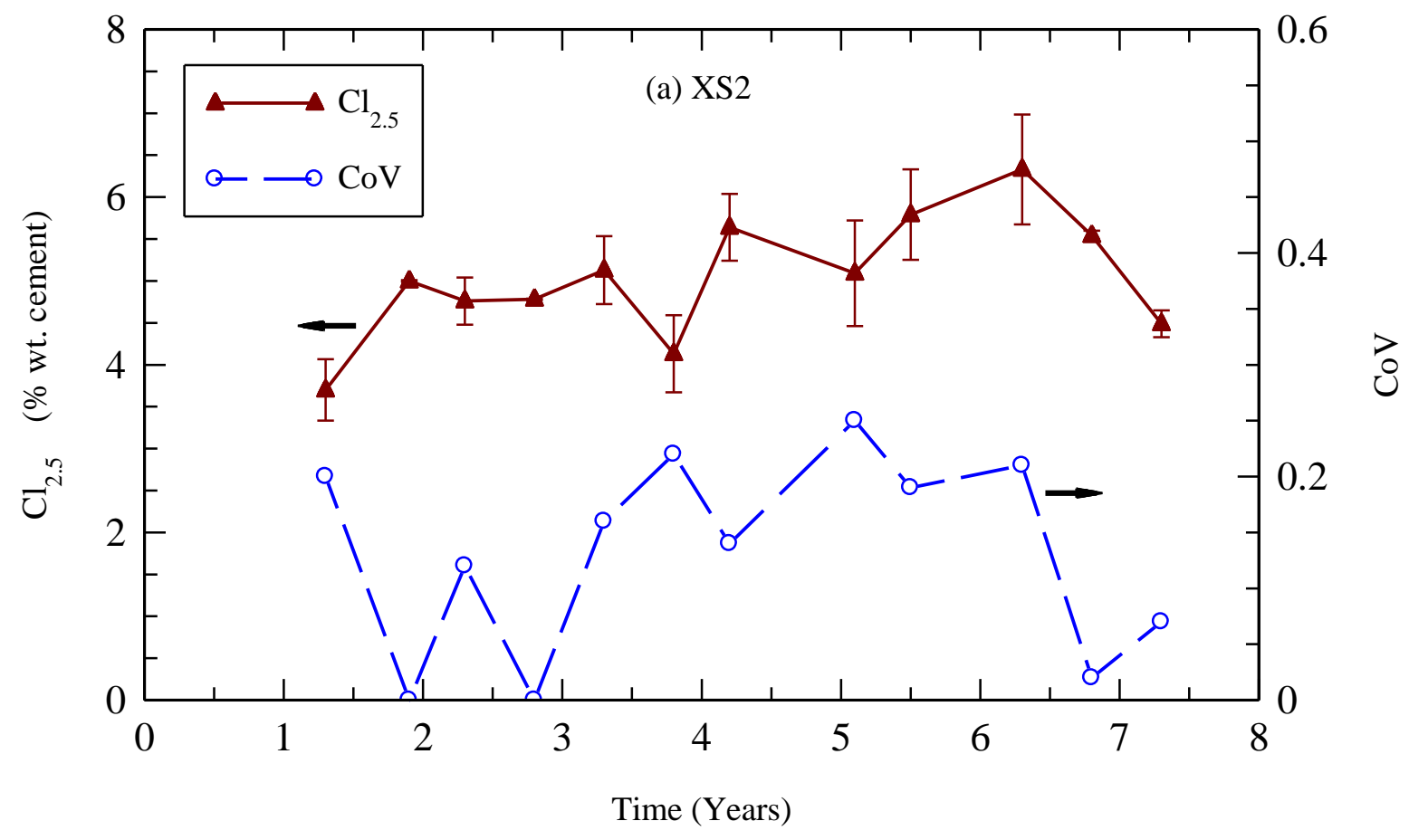

(b)

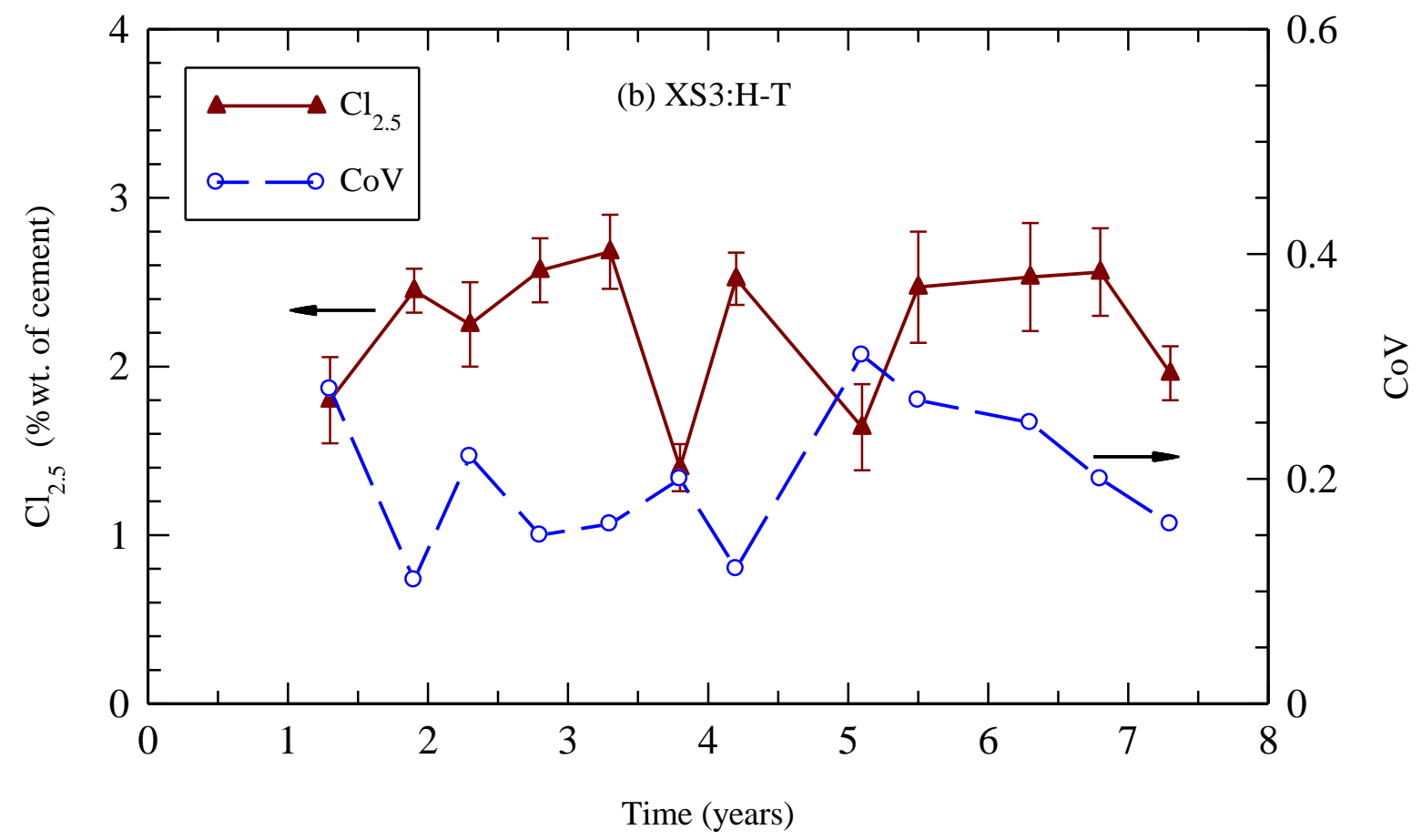


(c)



(d)

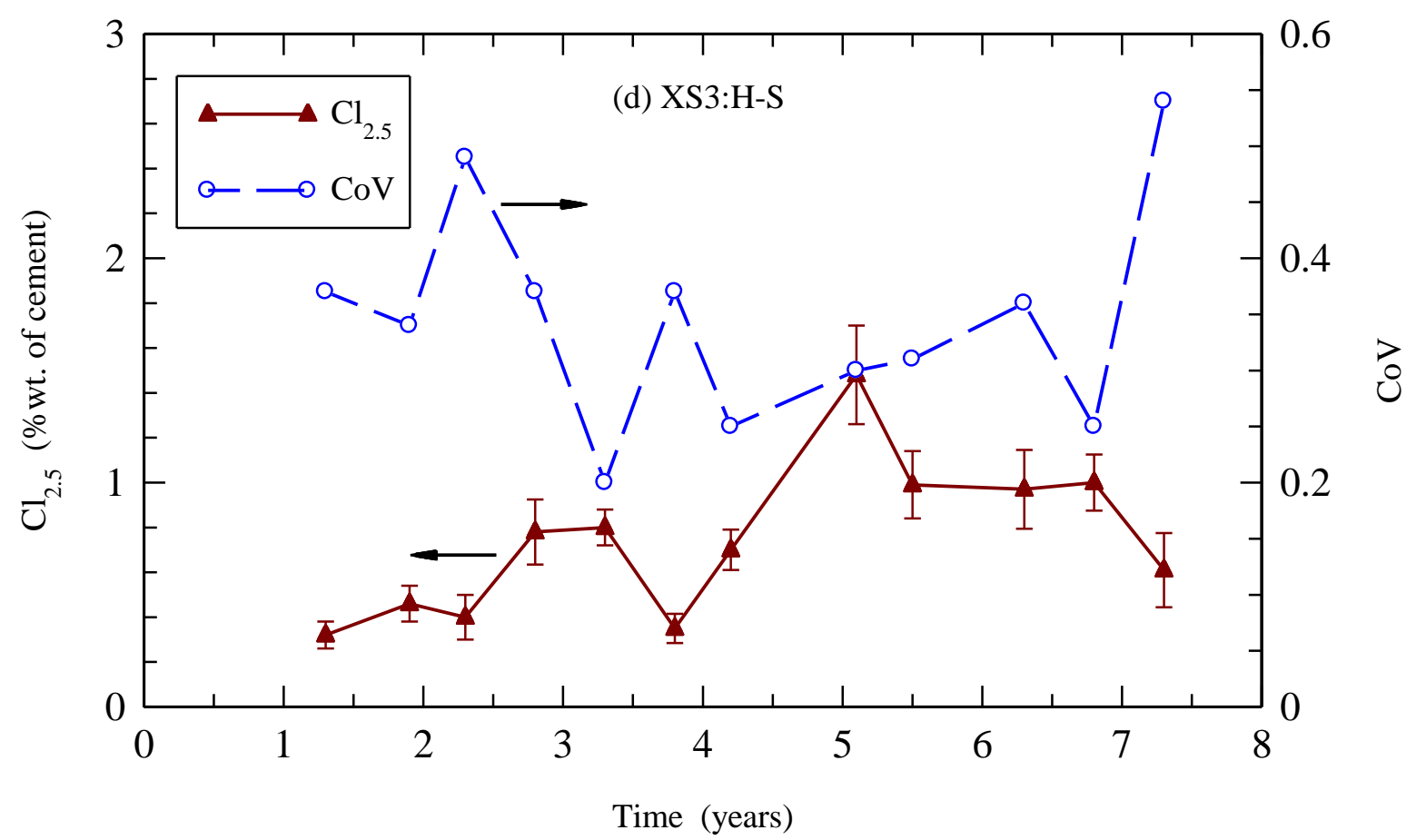

Fig. 5 
(a)

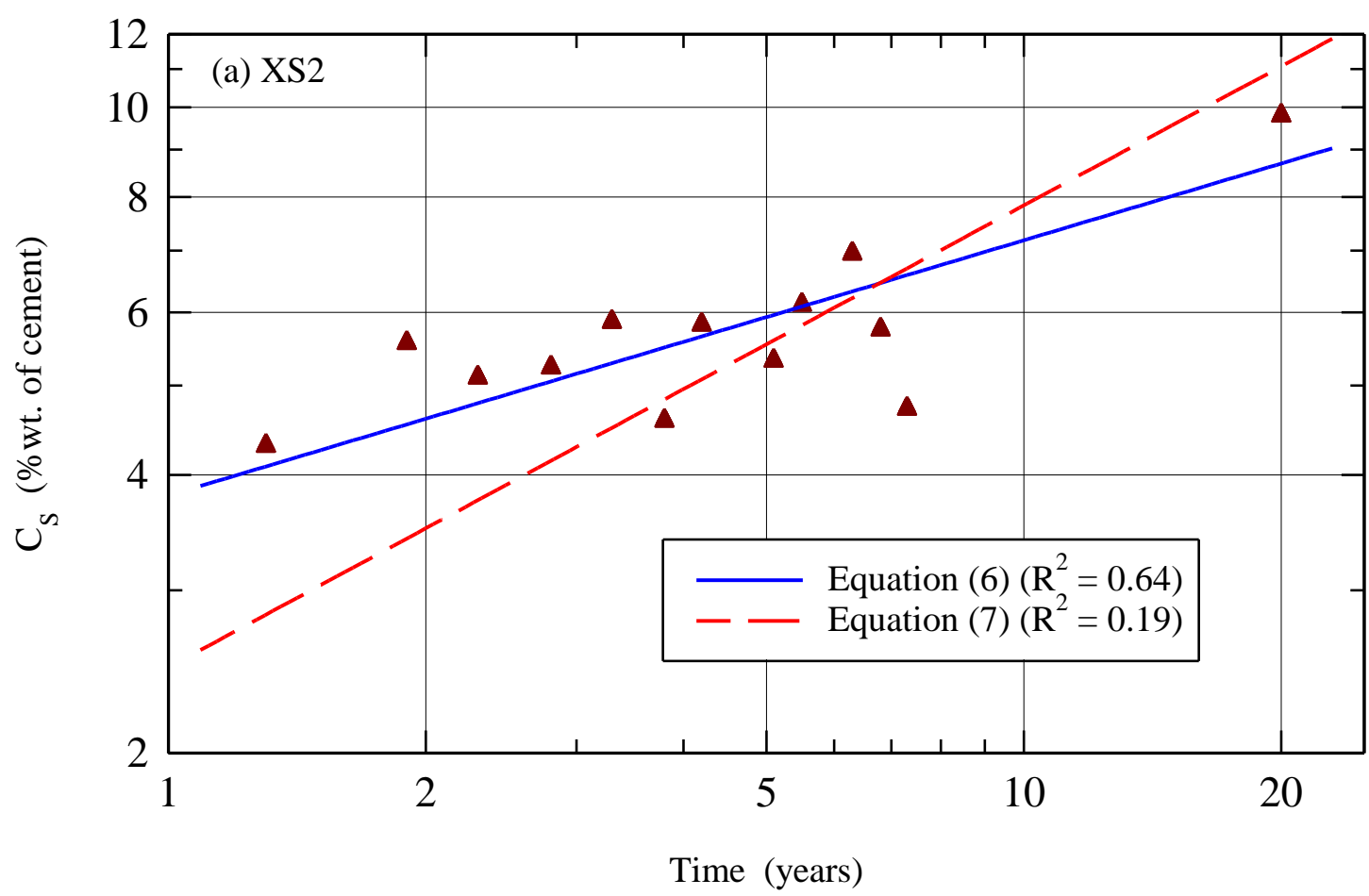

(b)

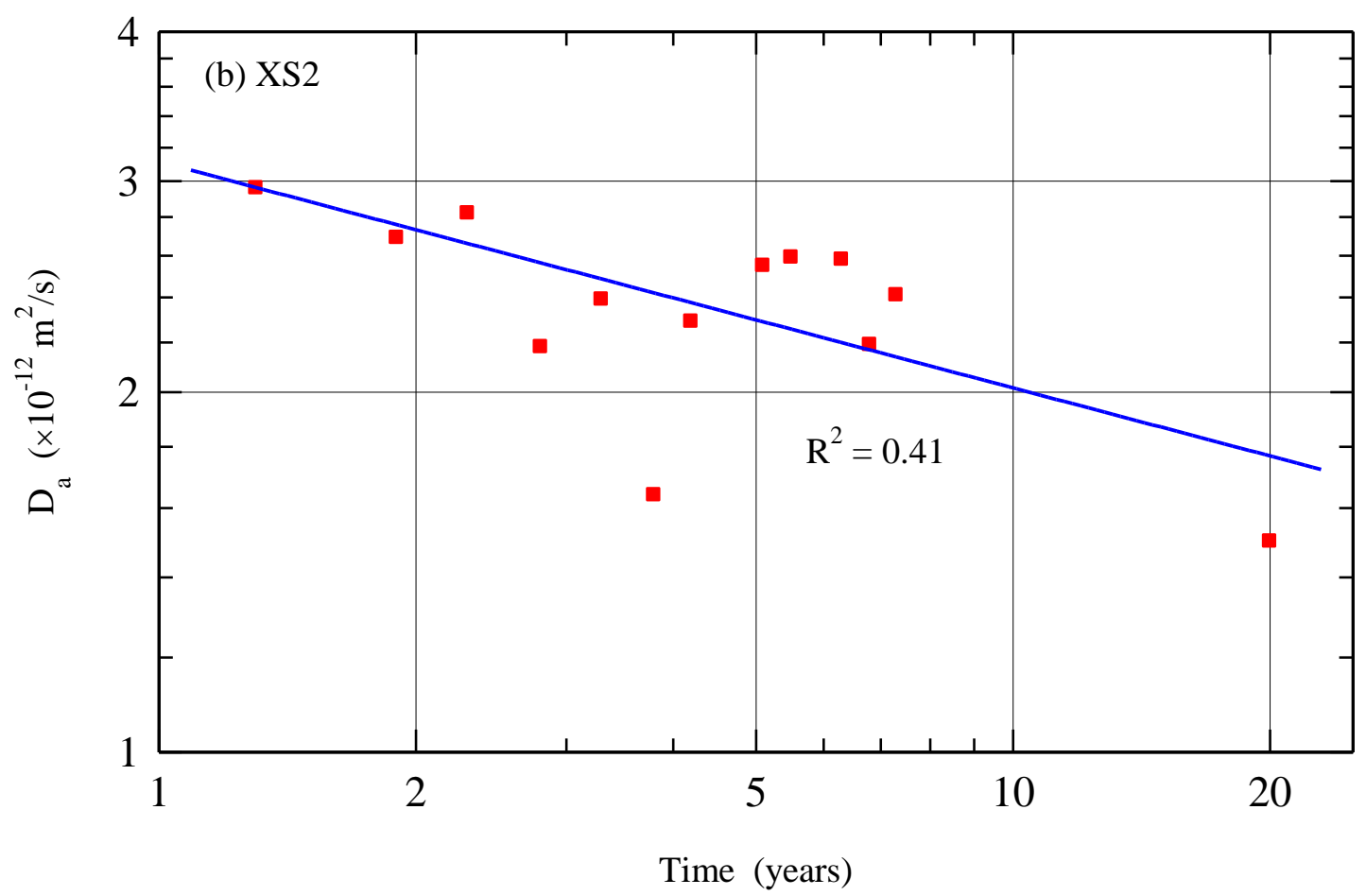

Fig. 6 
(a)



(b)

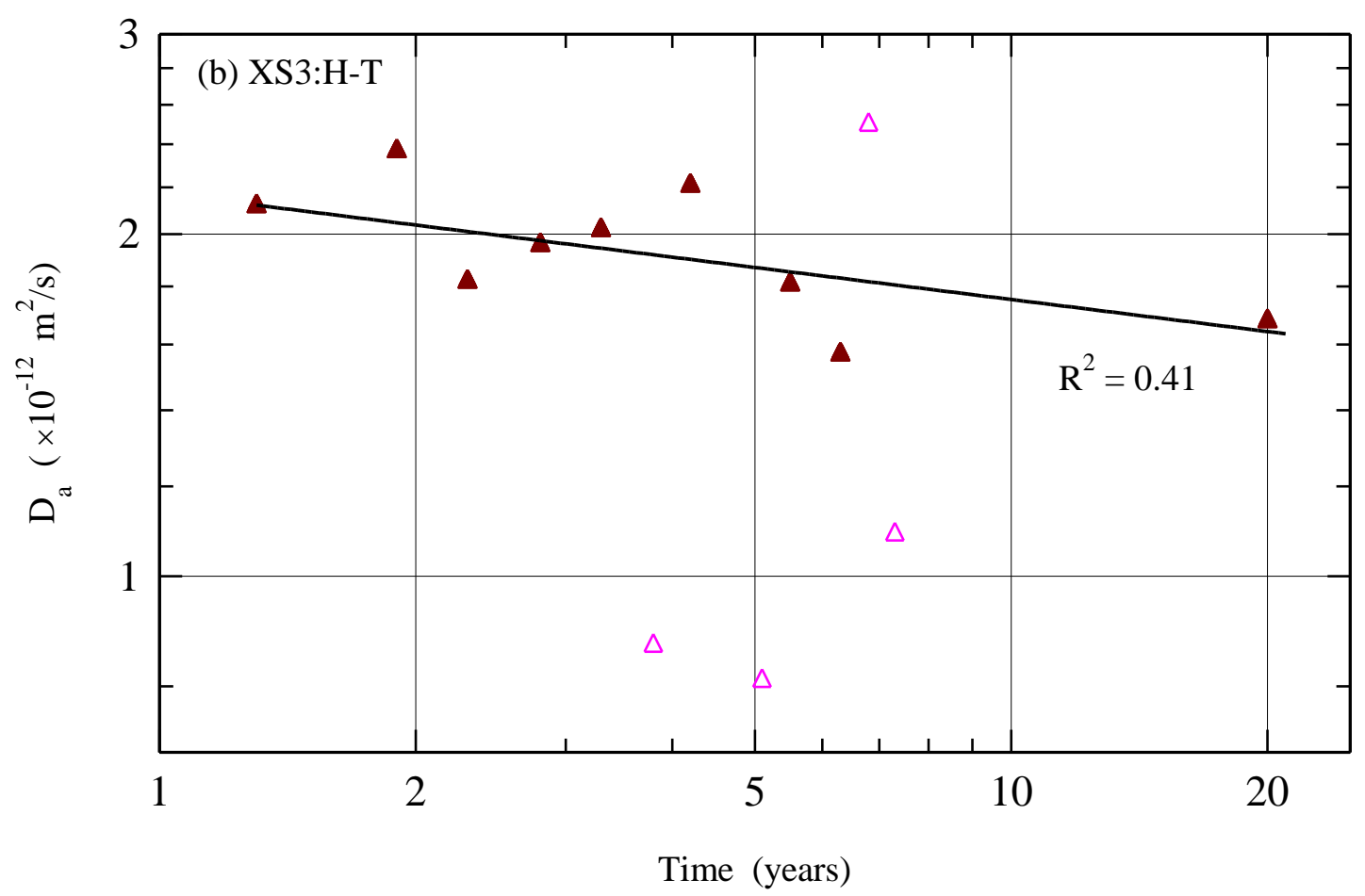

Fig. 7 
(a)

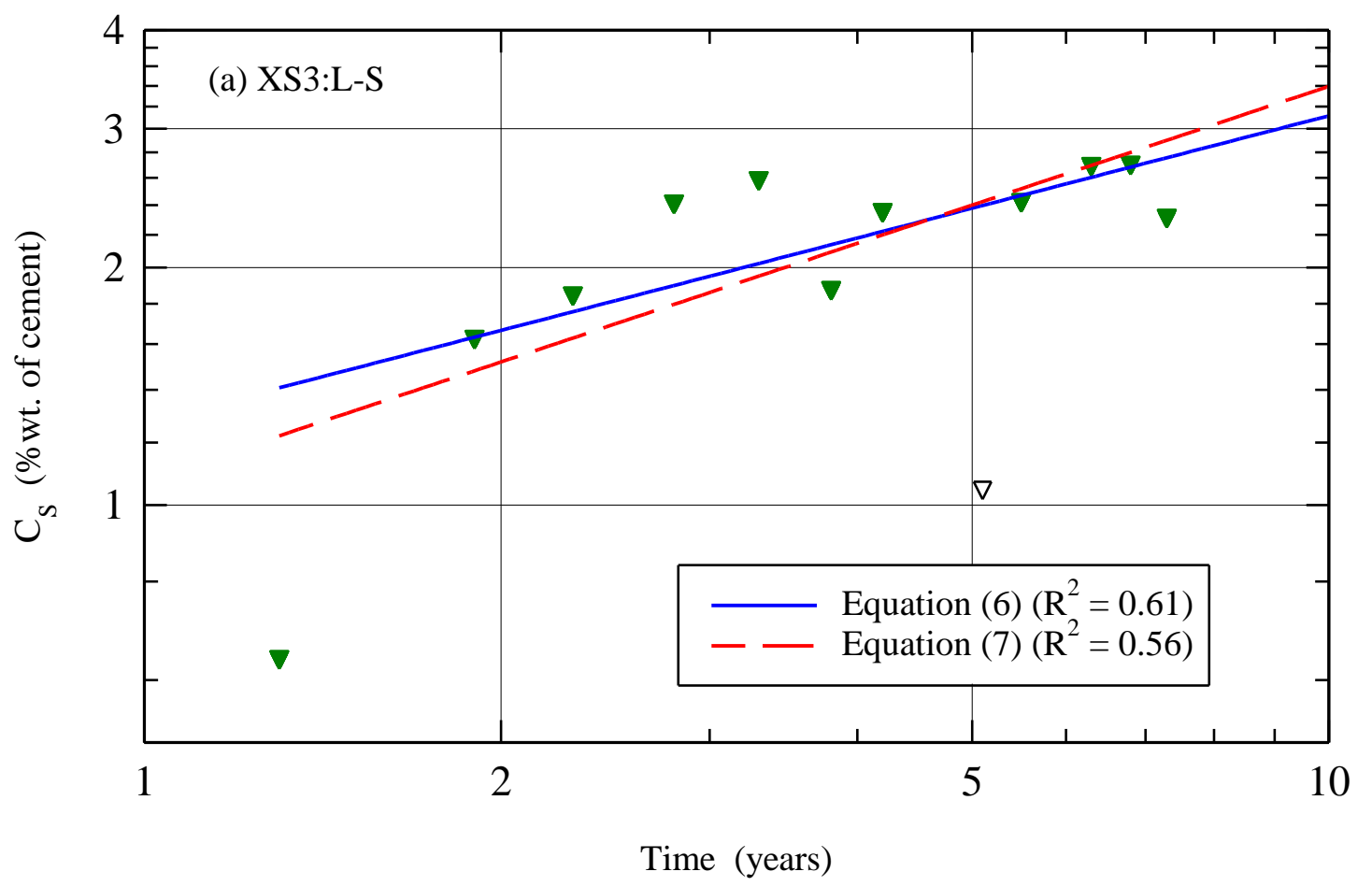

(b)

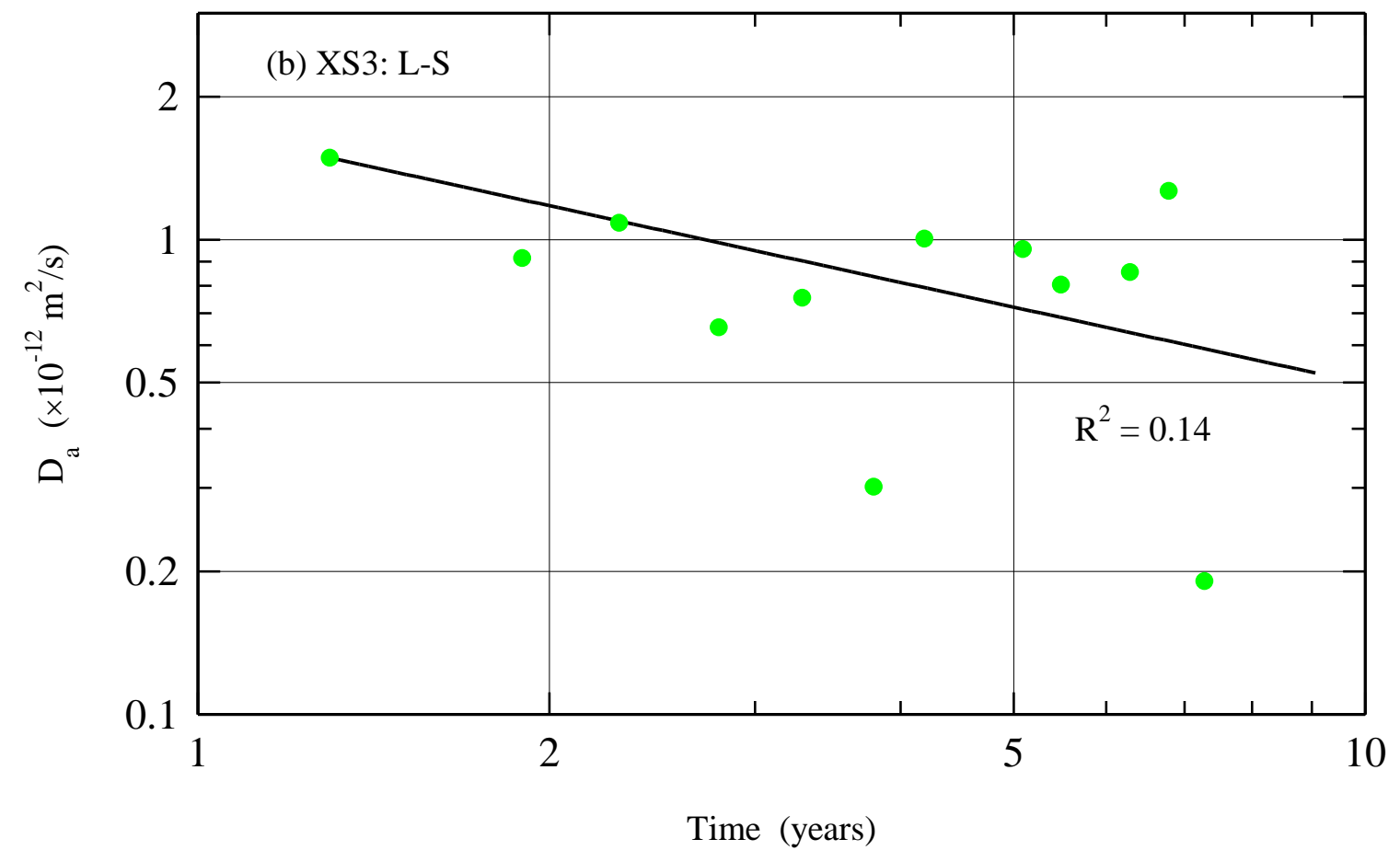

Fig. 8 


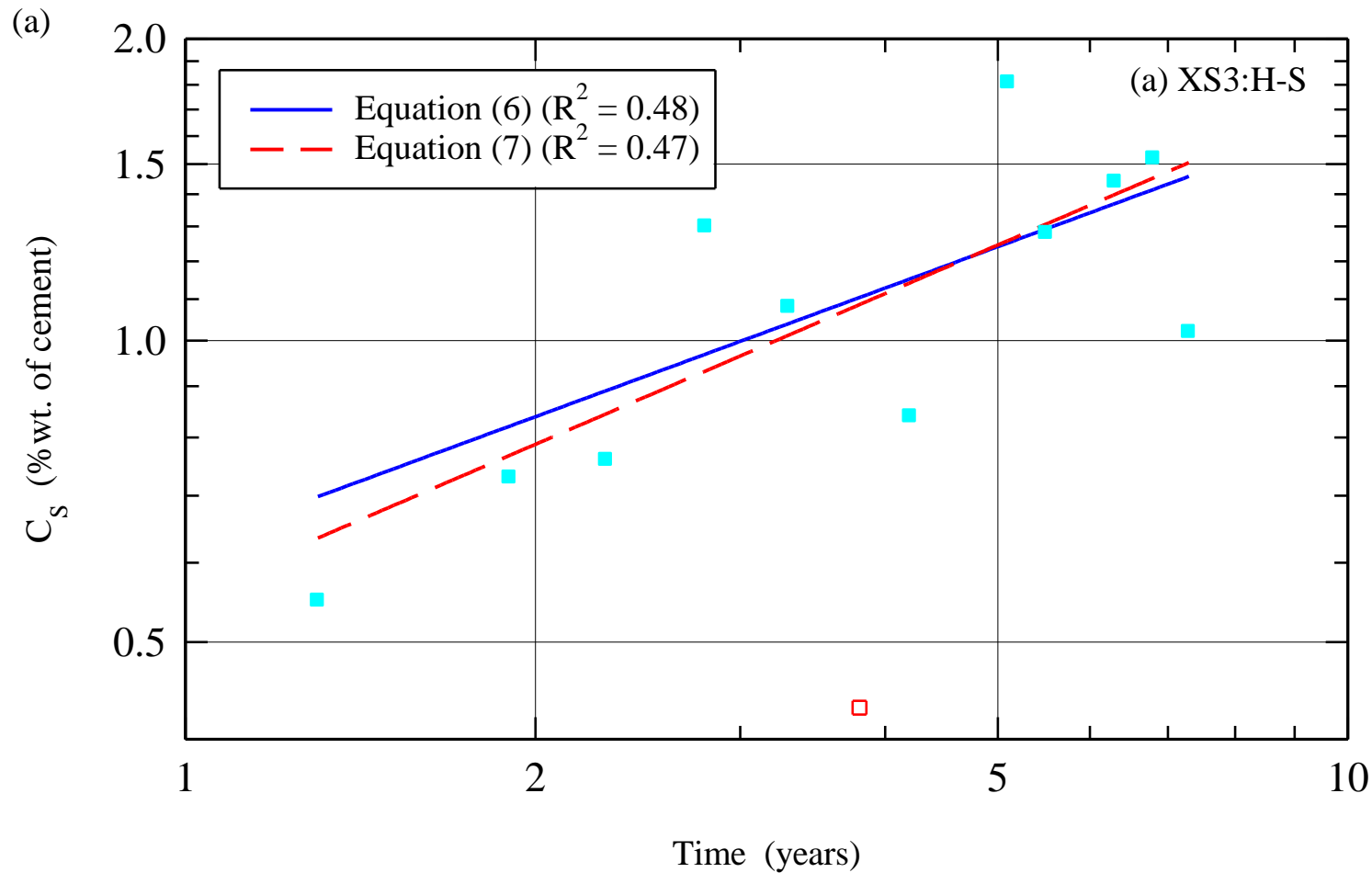

(b)

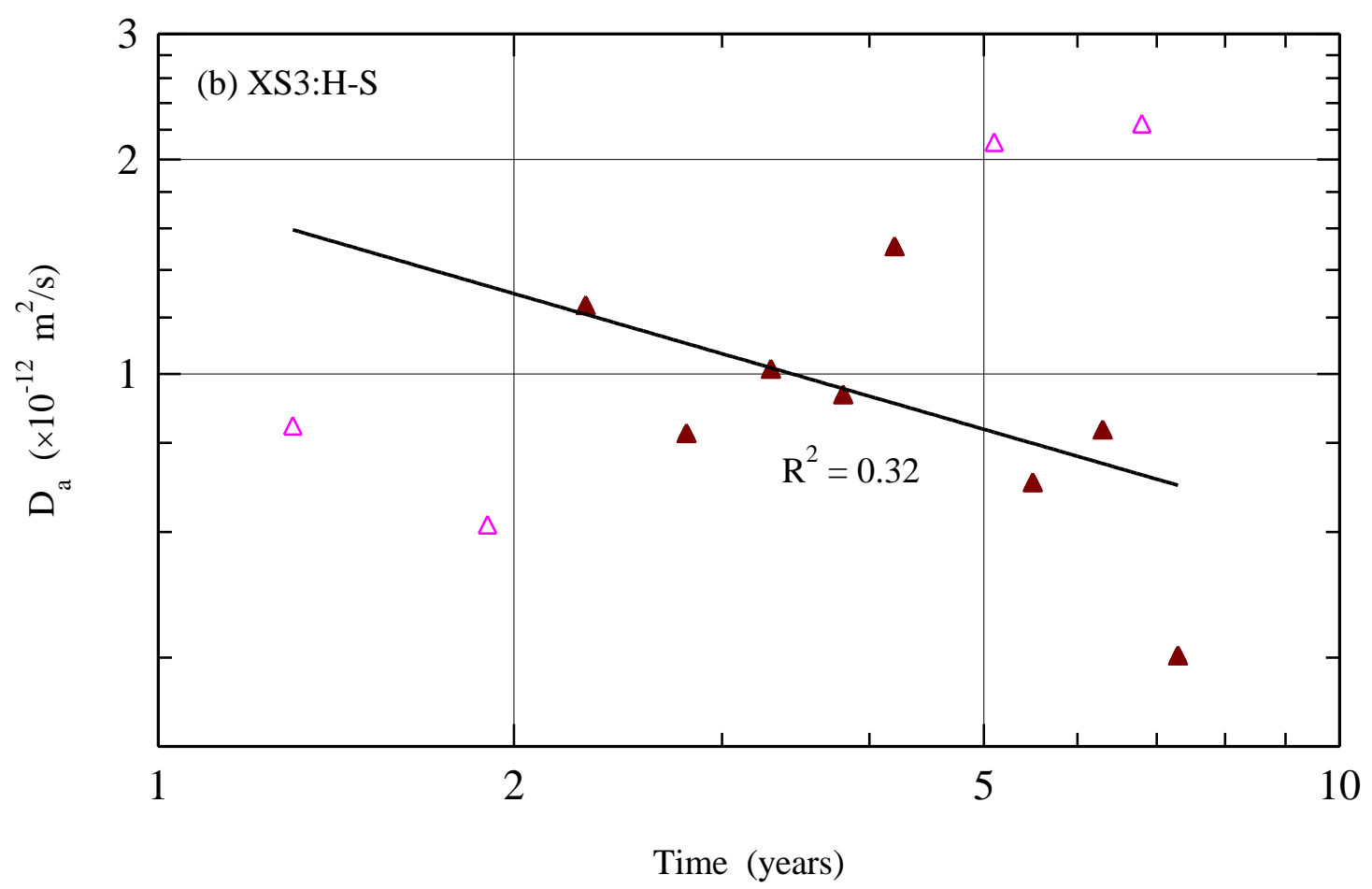

Fig. 9 


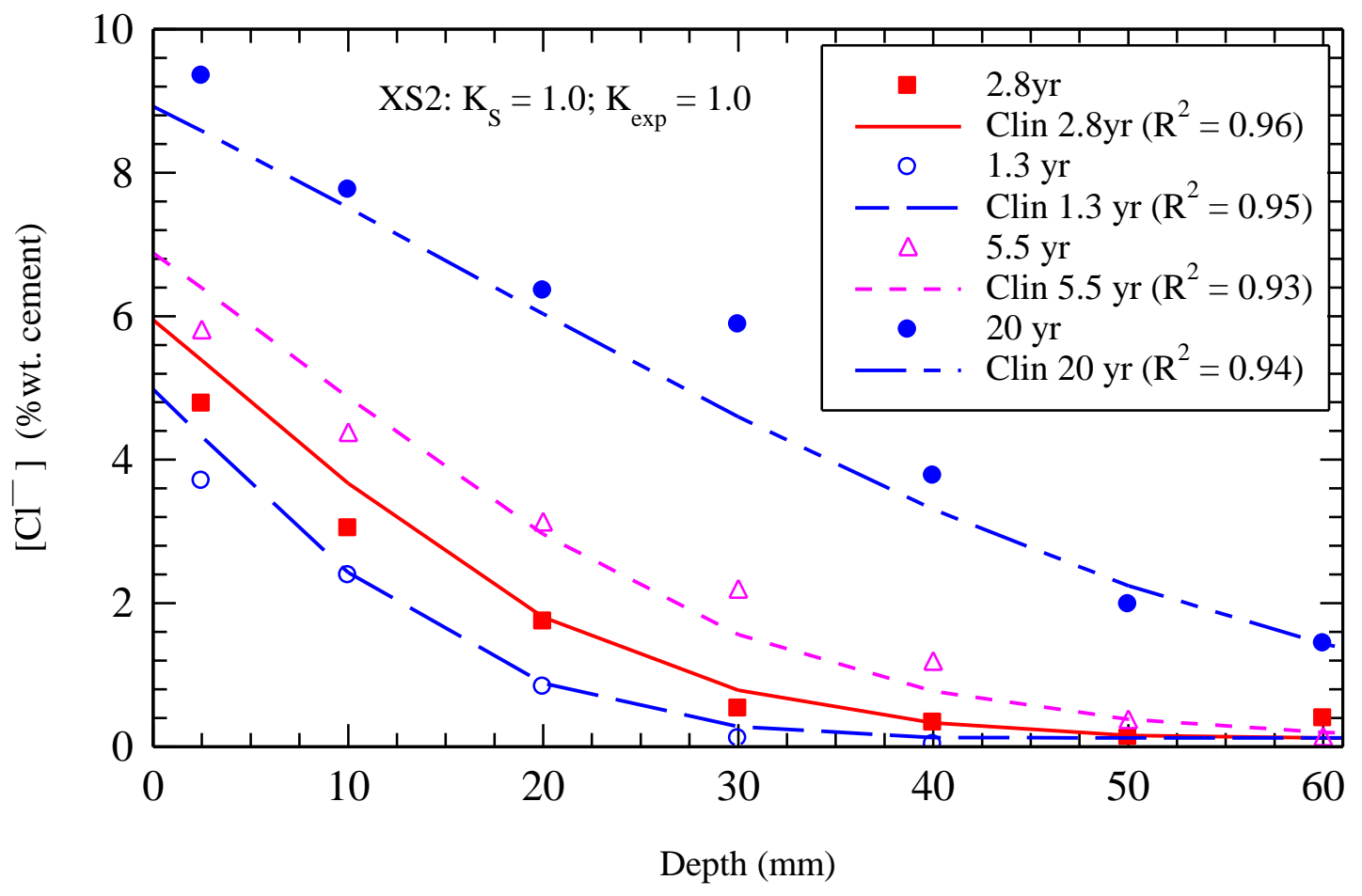

Fig. 10 
(a)

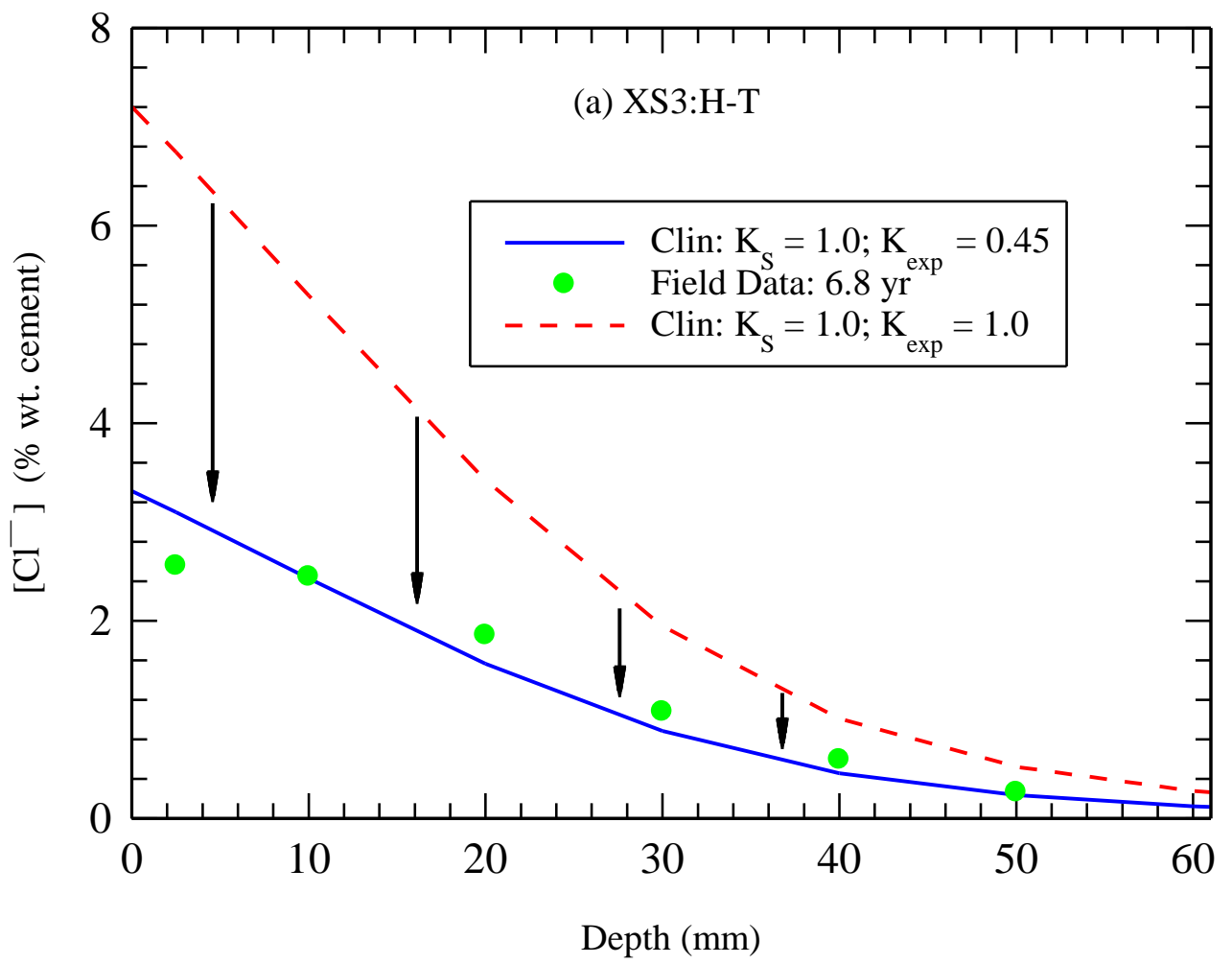

(b)

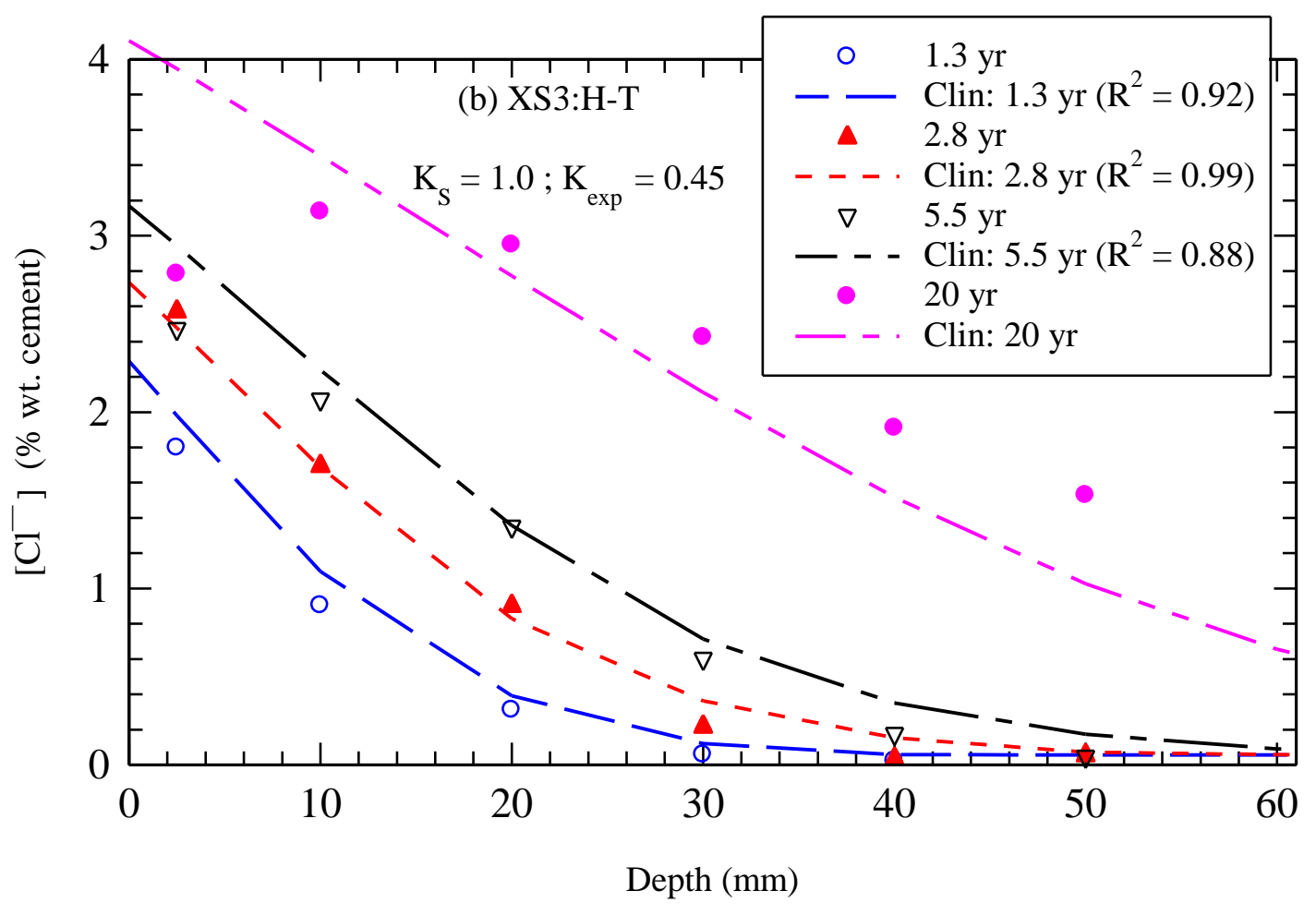

Fig. 11 
(a)

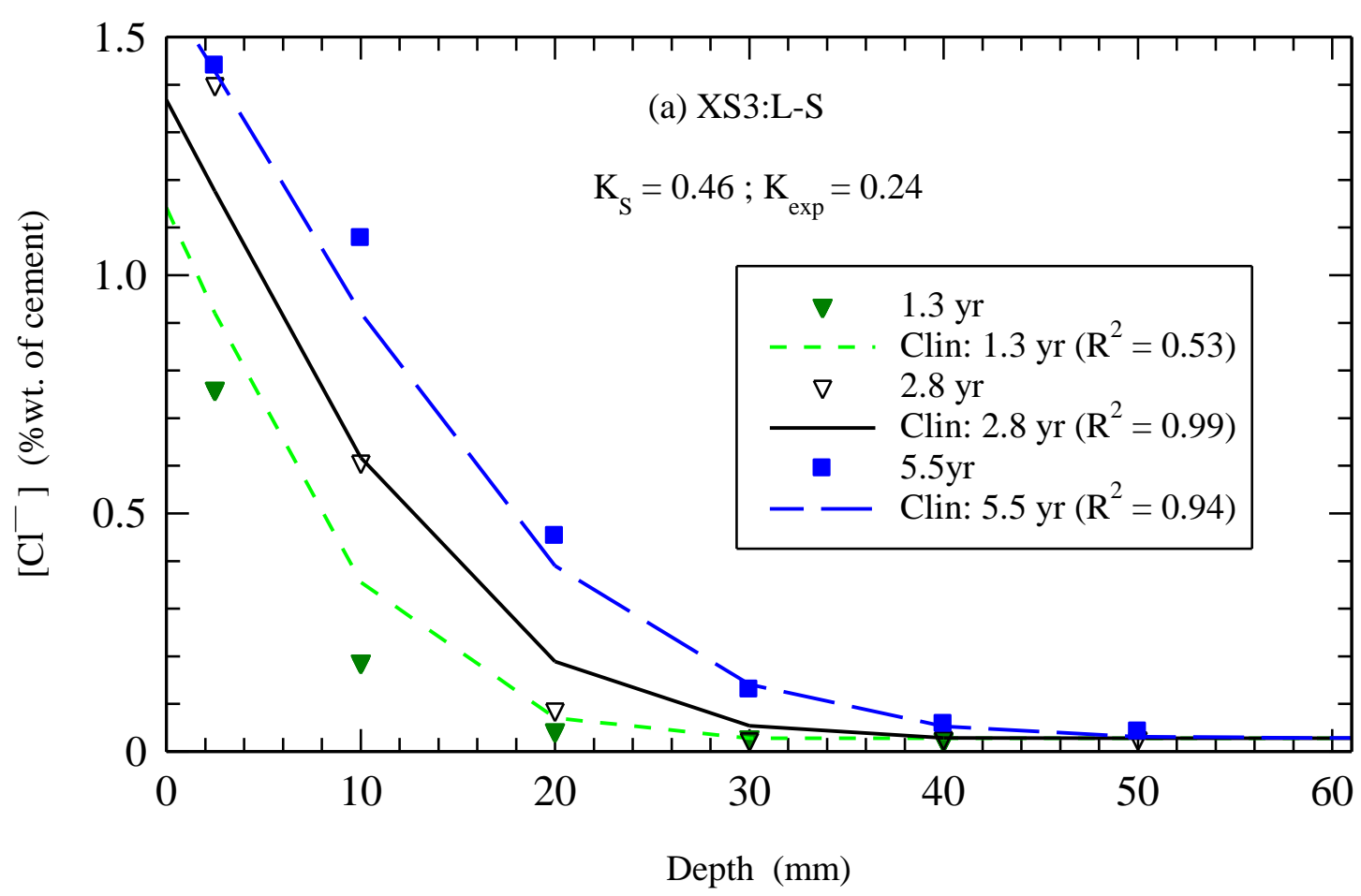

(b)

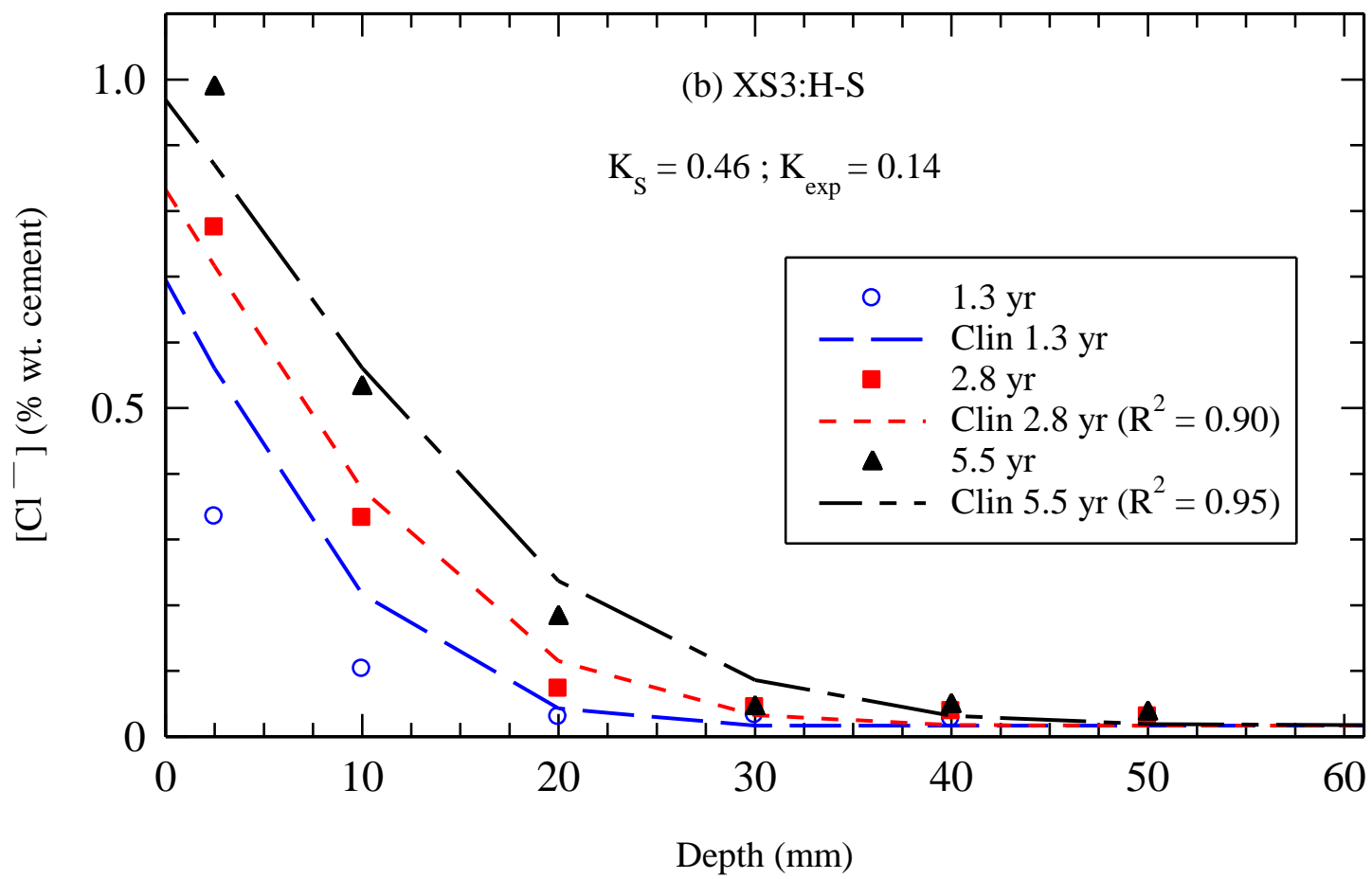

Fig. 12 
(a)

(b)
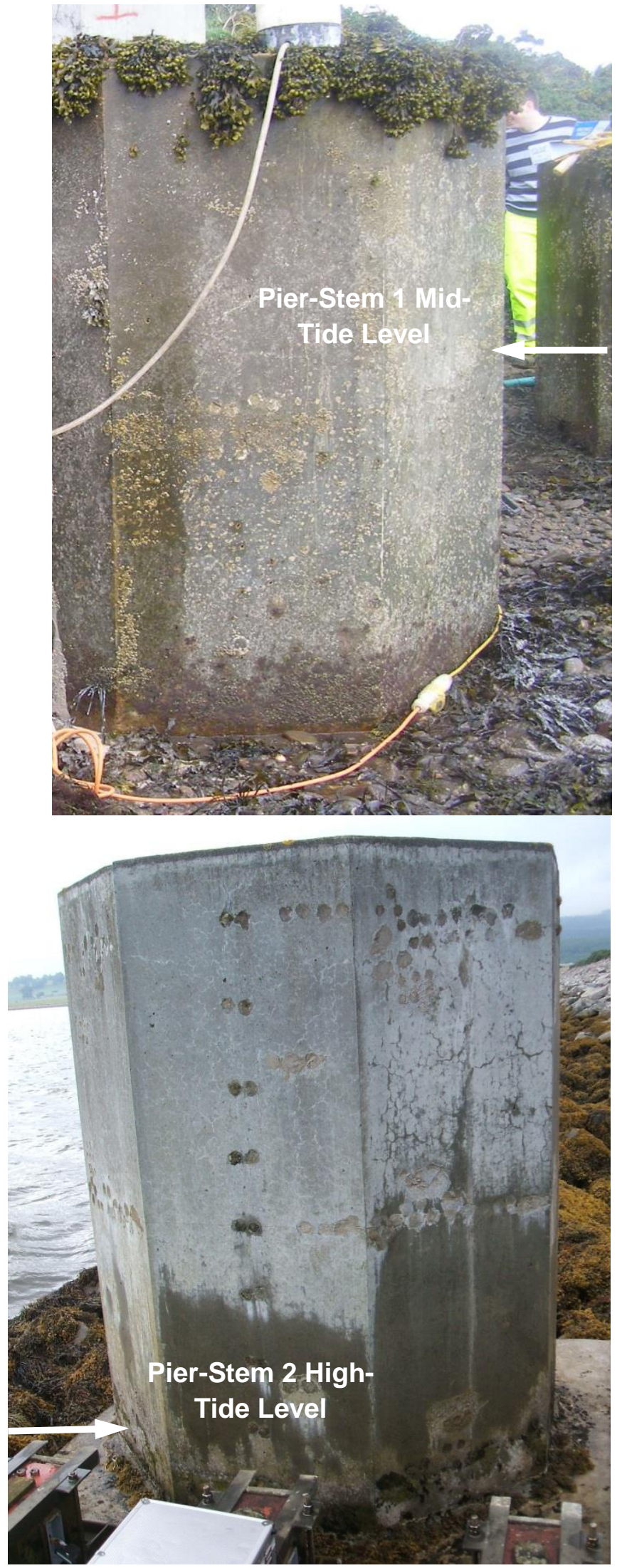

Fig. 13 